NBER WORKING PAPER SERIES

\title{
NATIONAL SOVEREIGNTY IN AN INTERDEPENDENT WORLD
}

\author{
Kyle Bagwell \\ Robert W. Staiger \\ Working Paper 10249 \\ http://www.nber.org/papers/w10249 \\ NATIONAL BUREAU OF ECONOMIC RESEARCH \\ 1050 Massachusetts Avenue \\ Cambridge, MA 02138 \\ January 2004
}

We thank Alberto Martin, seminar participants at Notre Dame, and especially Stephen Krasner and Donald Regan for many helpful comments, and the National Science Foundation for support. The views expressed herein are those of the authors and not necessarily those of the National Bureau of Economic Research.

(C2004 by Kyle Bagwell and Robert W. Staiger. All rights reserved. Short sections of text, not to exceed two paragraphs, may be quoted without explicit permission provided that full credit, including $@$ notice, is given to the source. 
National Sovereignty in an Interdependent World

Kyle Bagwell and Robert W. Staiger

NBER Working Paper No. 10249

January 2004

JEL No. F1

\section{$\underline{\text { ABSTRACT }}$}

What are the sovereign rights of nations in an interdependent world, and to what extent do these rights stand in the way of achieving important international objectives? These two questions rest at the heart of contemporary debate over the role and design of international institutions as well as growing tension between globalization and the preservation of national sovereignty. In this paper, we propose answers to these two questions. We do so by first developing formal definitions of national sovereignty that capture features of sovereignty emphasized in the political science literature. We then utilize these definitions to describe the degree and nature of national sovereignty possessed by governments in a benchmark (Nash) world in which there exist no international agreements of any kind. And with national sovereignty characterized in this benchmark world, we then evaluate the extent to which national sovereignty is compromised by international agreements with specific design features. In this way, we delineate the degree of tension between national sovereignty and international objectives and describe how that tension can be minimized - and in principle at times even eliminated - through careful institutional design.

Kyle Bagwell

Department of Economics

Columbia University

420 West 118th Street, IAB

New York, NY 10027

and NBER

kwb8@columbia.edu

Robert W. Staiger

Department of Economics

The University of Wisconsin

1180 Observatory Drive

Madison, WI 53705

and NBER

rstaiger@wisc.edu 
"Of all the rights possessed by a nation, that of sovereignty is doubtless the most important." Emmerich de Vattel in The Law of Nations, as quoted in Jeremy Rabkin, Why Sovereignty Matters, p. 27.

\section{Introduction}

What are the sovereign rights of nations in an interdependent world, and to what extent do these rights stand in the way of achieving important international objectives? These two questions rest at the heart of contemporary debate over the role and design of international institutions as well as growing tension between globalization and the preservation of national sovereignty. But answers are elusive. This is attributable in part to the fact that national sovereignty is a complex notion, reflecting a number of different features. And it is attributable as well to the fact that nations interact in increasingly complex and interdependent ways, making it difficult to draw clear distinctions between international and domestic affairs.

In this paper, we propose answers to these two questions. We do so by first developing formal definitions of national sovereignty that capture features of sovereignty emphasized in the political science literature. We then utilize these definitions to describe the degree and nature of national sovereignty possessed by governments in a benchmark (Nash) world in which there exist no international agreements of any kind. And with national sovereignty characterized in this benchmark world, we then evaluate the extent to which national sovereignty is compromised by international agreements with specific design features. In this way, we delineate the degree of tension between national sovereignty and international objectives and describe how that tension can be minimized - and in principle at times even eliminated - through careful institutional design.

We focus our formal analysis on two prominent features of national sovereignty: the ability of governments to exercise unilateral control over their policy instruments and the issues that are important to them, and to operate without outside influence in their internal affairs. The first feature reflects the extent to which a government can dictate the outcomes over the things it cares about, and the second feature reflects the extent that a government is free to determine its own affairs when other governments are indifferent to its choices. Adopting a taxonomy described by Krasner (2001), we associate interdependence sovereignty with the first feature and Westphalian sovereignty with 
the second. With our formal definitions of interdependence sovereignty and Westphalian sovereignty in hand, we then turn to a characterization of the nature and degree of sovereignty that governments possess in various economic environments and institutional settings.

We begin this characterization by describing a two-country two-good general equilibrium trading environment in which each government makes choices over its import tariff and a set of domestic regulations. In this trading environment, the interdependence across countries is pecuniary in nature. To identify the degree of sovereignty that governments possess in this environment in the absence of an international agreement, we show that each government's policy choices in the Nash equilibrium can be partitioned into a choice of market access - the volume of imports it would accept at a particular foreign exporter (world) price - given the other government's policies, and then a choice of how best to use its policy instruments to achieve its objectives while delivering this level of market access (e.g., high tariffs and stringent domestic regulations or low tariffs and lax domestic regulations). This partition is useful, because it enables us to establish that governments typically possess neither interdependence sovereignty nor Westphalian sovereignty in their market access choices in the absence of international agreements, but that they enjoy both interdependence and Westphalian sovereignty in all other choices in this environment. Moreover, we show that this partition identifies the maximal sovereign choice set over all possible partitions of the government's policy choices. This in turn establishes a benchmark set of sovereign choices in the absence of international agreements - the mapping from market access levels to a government's policy choices for delivering those market access levels - from which we evaluate the impact that international agreements may have on national sovereignty in this environment.

We consider first an international trade agreement that specifies for each government the negotiated level of its tariff and possibly also a subset of its regulations. Such an agreement is natural to consider in this environment, because as we indicate the Nash policy choices of the two governments are inefficient from an international perspective, and so with such an agreement the governments can potentially correct this inefficiency and thereby both enjoy higher welfare. While an agreement of this form directly compromises national sovereignty over the policy instruments that 
are directly negotiated, we argue that it may also indirectly compromise national sovereignty over the policy instruments that remain under unilateral control. In fact, our first main result is to show that any international trade agreement that moves a government away from its unilateral bestresponse policies by specifying permissible levels for a subset of that government's policies must compromise that government's sovereignty over at least as many instruments as it preserves. This result suggests a stark tradeoff between international efficiency - the attainment of which in general requires an international trade agreement in this environment - and national sovereignty.

We show, however, that this tradeoff is not inevitable. In particular, our second main result is that an international trade agreement that takes the form of a market access agreement, under which each government agrees to provide a specified level of market access to its trading partner but is otherwise free to choose its policies as it sees fit, can achieve international efficiency without compromising national sovereignty. In effect, a market access agreement has the domestic and foreign governments making joint determinations over the things for which they each lacked sovereignty in the Nash equilibrium, but each government makes unilateral choices over the things for which it enjoyed sovereignty in the Nash equilibrium. As the international inefficiency in this environment amounts to insufficient market access, a market access agreement can in this way correct the international inefficiency without compromising national sovereignty.

We next extend the two-country trade model to a three-country setting. In particular, we introduce a second foreign country, so that the domestic country now has two trading partners. In this environment, the interdependence across countries is still pecuniary in nature, but there is now the possibility that the domestic country might set discriminatory tariffs against each of its trading partners. This allows us to consider the implications for national sovereignty of an international agreement to abide by a non-discrimination rule, such as the MFN requirement to which GATT/WTO members must submit when they join. We ask: Is the domestic government's sovereignty compromised if it agrees to abide by a non-discrimination rule? Broadly speaking, we may think of the answer to this question as indicating whether a government's national sovereignty would be compromised if it joined the GATT/WTO but made no market access commitments, and 
therefore simply agreed to abide by the MFN requirement of the GATT/WTO.

Our third main result is that abiding by the non-discrimination rule involves no compromise of national sovereignty. Intuitively, the MFN requirement is inconsistent with certain market access choices that would be feasible under discriminatory tariffs. But market access choices lack interdependence sovereignty and Westphalian sovereignty even absent any international agreement, so the restriction on these choices implied by MFN does not compromise national sovereignty. And given MFN-consistent market access choices, the MFN requirement has no bearing on the remaining choices of a government, which are its sovereign choices, because the restriction to MFN tariffs does not affect the feasible set for these choices.

Thus far we have maintained the assumption that each country is "large" in world markets, so that its policy choices affect foreign exporter (world) prices. Characterizing the sovereignty of "small" countries - who by definition cannot alter world prices when they alter their policies - is of some interest in its own right. As we show, small countries differ from large countries in two ways. On the one hand, small countries suffer from an extreme lack of interdependence sovereignty in their (Nash) market access choices, in that the foreign exporter prices they face are completely determined by outside forces beyond their unilateral control. On the other hand, small countries enjoy Westphalian sovereignty in their (Nash) market access choices: a small country's market access choices are a matter of indifference to its trading partners, because these choices have no bearing on foreign exporter prices.

When we extend the three-country model to allow for the possibility that some countries are small, we find that a direct tradeoff between international efficiency and national sovereignty now arises, unless non-discriminatory policies are adopted. In effect, if small countries are asked to make market access commitments, their Westphalian sovereignty will be compromised. If this is to be avoided, then small countries must be left unconstrained to choose their best-response policies in any international agreement. This requirement, though, is consistent with international efficiency only when tariffs also conform to the MFN requirement (which itself involves no compromise of national 
sovereignty). As a consequence, we find that a non-discrimination rule can allow governments to sidestep the efficiency/sovereignty tradeoff that would otherwise exist in this extended setting, and we suggest that the MFN requirement is therefore "complementary" to preserving small-country sovereignty in the following sense: the (Westphalian) sovereignty of small countries can be preserved under an internationally efficient agreement only if that agreement abides by the MFN requirement. More broadly, our three-country results therefore suggest that a non-discrimination rule coupled with a market access agreement can facilitate the attainment of internationally efficient outcomes which do not compromise national efficiency.

When viewed together, these results have potentially important implications for the design of the World Trade Organization (WTO) and its predecessor, the General Agreement on Tariffs and Trade (GATT). The GATT/WTO has from its inception been concerned most fundamentally with non-discriminatory market access commitments, and it has traditionally sought to anchor these commitments with negotiations over border measures (e.g., tariffs) that are "multilateralized" through the MFN requirement. But this tradition is being eroded on two fronts. First, the extent and importance of discriminatory trade agreements (permitted by GATT/WTO exceptions to its MFN requirement) has increased dramatically in recent decades. And second, increasingly the WTO is thought of as a potential forum for the negotiation of international commitments on a host of nonborder policies that are deemed to have important market access consequences, ranging from labor standards to environmental regulations to competition policy. Our results highlight the fundamental implications of these developments for the potential conflicts between international efficiency and national sovereignty within the WTO. Specifically, as our results indicate, the further the WTO departs from facilitating agreements that take the form of non-discriminatory market access commitments, the more it is likely to pose a (direct and indirect - and in principle, unnecessary) threat to the sovereignty of its member governments.

Finally, we extend our analysis from the case where the interdependence across countries is of a pecuniary nature to discuss briefly the case where interdependence takes a non-pecuniary form. 
This case is the focus of the large literature on fiscal federalism. ${ }^{1}$ An important distinction that arises here is that pecuniary externalities give rise to inefficiency only if agents (in this case governments) wield market power and can therefore affect prices (in this case world prices) with their actions, while with non-pecuniary externalities inefficiency typically arises even when each agent is small and there is no market power affecting decisions. As we argue, this distinction creates the possibility of an unavoidable tradeoff between international efficiency and (Westphalian) sovereignty in the presence of international non-pecuniary interdependence when some countries are small that, as we have described above, is not present in the case of international pecuniary interdependence. This is because even small countries may have to make commitments regarding an international nonpecuniary externality in order for the world to attain international efficiency, and these countries then sacrifice their (Westphalian) sovereignty as a consequence.

On the basis of this final observation we argue that, when it comes to issues of national sovereignty as they arise in the context of efforts to address international "problems," not all international problems are alike. In particular, international problems that are fundamentally associated with trade have a particular structure - they concern international pecuniary externalities - which implies the absence of any inherent conflict between international efficiency and national sovereignty. By contrast, confronting international problems that derive from international nonpecuniary externalities is likely to pose a more direct efficiency/sovereignty tradeoff.

This paper builds on our earlier work. The basic two-country model with which we begin in section II is developed in Bagwell and Staiger (2001). The three-country model developed in section V extends the three-country model of Bagwell and Staiger (1999) to incorporate domestic regulatory policies. In the present paper, however, we build from these models to provide a first formal and systematic analysis of the implications of trade agreements for national sovereignty. This requires introducing formal definitions of sovereignty, and applying these definitions to evaluate the degree and nature of sovereignty possessed by governments in a variety of economic environments

\footnotetext{
${ }^{1}$ The seminal contribution on fiscal federalism is Oates (1972). More recent related contributions in an international context include Alesina and Spolaore (1997) and Alesina, Angeloni and Etro (2003).
} 
and institutional settings, an exploration that no earlier work (neither ours, nor that of others) has attempted.

The rest of the paper proceeds as follows. Section II describes the basic two-country model and characterizes the Nash and efficient policies. Section III develops our formal definitions of sovereignty, and characterizes the nature and degree of sovereignty in the Nash equilibrium. Section IV considers how national sovereignty is affected under international trade agreements that adopt alternative designs. Section V extends the modeling environment to a three-country setting, and considers the implications of a non-discrimination rule and of the existence of small countries for our sovereignty results. Section VI discusses briefly the case of international non-pecuniary interdependence. Section VII concludes, while an Appendix contains more technical proofs.

\section{Tariffs and Regulations in a Two-Country Trade Model}

Our starting point is the two-country two-good competitive general equilibrium model adapted to allow for the possibility of both tariff and domestic regulatory policy choices as developed in Bagwell and Staiger (2001). We sketch briefly the essentials of that model here.

\section{II.1: The Basic Two-Country Trade Model}

The home country exports good $y$ to the foreign country in exchange for imports of good $x$. The local relative price of good $x$ to good $y$ in the home (foreign) country is denoted by $p\left(p^{*}\right)$, where here and throughout "*" is used to denote foreign variables. The "world price" (i.e., relative exporter price or terms of trade ) is denoted by $p^{w}$, and international arbitrage links each country's local price to the world price in light of its tariff according to $p=\tau p^{w} \equiv p\left(\tau, p^{w}\right)$ and $p^{*}=p^{w} / \tau^{*} \equiv p^{*}\left(\tau^{*}, p^{w}\right)$, where $\tau \quad\left(\tau^{*}\right)$ is one plus the ad valorem import tariff of the home (foreign) country. In addition to its tariff, each country also imposes a vector of local regulations, $\boldsymbol{r}$

(with length $R$ ) for the home country and $\boldsymbol{r}^{*}$ (with length $R^{*}$ ) for the foreign country, that may impact local production and/or consumption decisions at given prices. Each country's vector of local regulations therefore acts as a vector of "shift" parameters in its import demand and export supply 
functions, and we assume that these functions are differentiable in their respective regulation levels.

Incorporating each country's vector of regulations into its import demand and export supply functions, we denote these functions for the home country by $M\left(\boldsymbol{r}, p, p^{w}\right)$ and $E\left(\boldsymbol{r}, p, p^{w}\right)$, respectively, and for the foreign country by $M^{*}\left(\boldsymbol{r}^{*}, p^{*}, p^{w}\right)$ and $E^{*}\left(\boldsymbol{r}^{*}, p^{*}, p^{w}\right)$, respectively. The home and foreign budget constraints may then be written as

$$
\begin{aligned}
& p^{w} M\left(\boldsymbol{r}, p, p^{w}\right)=E\left(\boldsymbol{r}, p, p^{w}\right) \\
& M^{*}\left(\boldsymbol{r}^{*}, p^{*}, p^{w}\right)=p^{w} E^{*}\left(\boldsymbol{r}^{*}, p^{*}, p^{w}\right) .
\end{aligned}
$$

The equilibrium world price, $\tilde{p}^{w}\left(\boldsymbol{r}, \tau, \boldsymbol{r}^{*}, \tau^{*}\right)$, is determined by the requirement of market clearing for $\operatorname{good} x$,

$$
M\left(\boldsymbol{r}, p\left(\tau, \tilde{p}^{w}\right), \tilde{p}^{w}\right)=E^{*}\left(\boldsymbol{r}^{*}, p^{*}\left(\tau^{*}, \tilde{p}^{w}\right)_{2} \tilde{p}^{w}\right)
$$

where we have made explicit the dependence of the local prices on the tariffs and the world prices, and market clearing for good $y$ is then implied by (1), (2) and (3). We assume that the Metzler and Lerner Paradoxes are ruled out, so that $d p / d \tau>0>d p^{*} / d \tau^{*}$ and $\partial \tilde{p}^{w} / \partial \tau<0<\partial \tilde{p}^{w} / \partial \tau^{*}$.

Finally, we represent the objectives of the home and foreign governments with the general functions $W\left(\boldsymbol{r}, p, \tilde{p}^{w}\right)$ and $W^{*}\left(\boldsymbol{r}^{*}, p^{*}, \tilde{p}^{w}\right)$, respectively. These objective functions reflect an important assumption: governments care about the regulatory (and tariff) choices of their trading partners only because of the trade impacts of these choices (and therefore only because of the impacts of these choices on the equilibrium world price $\tilde{p}^{w}$ ). As a consequence, the interdependence across countries is contained entirely in the determination of $\tilde{p}^{w}$, which is the only magnitude that enters both the domestic and the foreign objective function. This feature reflects in turn a simplifying assumption that we maintain for now, namely, that there are no international nonpecuniary externalities. In section VI, we relax this assumption and discuss briefly a setting in which important transboundary non-pecuniary externalities may also exist. 
We assume that, holding its regulations and its local price fixed, and provided that its regulations and local price do not imply autarky, each government would prefer an improvement in its terms of trade,

$$
W_{\tilde{p}^{w}}\left(\boldsymbol{r}, p, \tilde{p}^{w}\right)<0 \text { for } M\left(\boldsymbol{r}, p, \tilde{p}^{w}\right)>0 \text {, and } W_{\tilde{p}^{w}}^{*}\left(\boldsymbol{r}^{*}, p^{*}, \tilde{p}^{w}\right)>0 \text { for } M^{*}\left(\boldsymbol{r}^{*}, p^{*}, \tilde{p}^{w}\right)>0
$$

According to (4), governments like transfers of revenue from their trading partners. Our central analysis concerns the case in which trade takes place, and so (4) is relevant. However, we will report one important special case in which no trade takes place, and so we develop the analogue to (4) that applies in that circumstance. In the case of autarky, a change in the terms of trade holding its regulations and local price fixed should be irrelevant to a government, since there is no trade volume and continues to be no trade volume after the change, and so we assume as well that

$$
W_{\tilde{p}^{w}}\left(\boldsymbol{r}, p, \tilde{p}^{w}\right)=0 \text { for } M\left(\boldsymbol{r}, p, \tilde{p}^{w}\right)=0, \text { and } W_{\tilde{p}^{w}}^{*}\left(\boldsymbol{r}^{*}, p^{*}, \tilde{p}^{w}\right)=0 \text { for } M^{*}\left(\boldsymbol{r}^{*}, p^{*}, \tilde{p}^{w}\right)=0
$$

We leave government objectives otherwise unrestricted, and observe that these objectives are consistent with a wide variety of models of government behavior (see Bagwell and Staiger, 1999).

\section{II.2: Nash Policies}

In a world without international agreements, we assume that the Nash Policy Game characterizes the equilibrium policy choices of each government. In the Nash Policy Game, each government sets its trade and domestic regulatory policies simultaneously to maximize its objective function taking as given the policy choices of its trading partner. More specifically, the home government chooses its best-response policies by solving

Program 1: $\quad \operatorname{Max}_{\boldsymbol{r}, \tau} W\left(\boldsymbol{r}, p\left(\tau, \tilde{p}^{w}\left(\boldsymbol{r}, \tau, \boldsymbol{r}^{*}, \tau^{*}\right)\right), \tilde{p}^{w}\left(\boldsymbol{r}, \tau, \boldsymbol{r}^{*}, \tau^{*}\right)\right)$

taking $\boldsymbol{r}^{*}$ and $\tau^{*}$ as given, at the same time that the foreign government chooses its best-response policies by solving

Program 1*: $\operatorname{Max}_{\boldsymbol{r}^{*}, \tau^{*}} W^{*}\left(\boldsymbol{r}^{*}, p^{*}\left(\tau^{*}, \tilde{p}^{w}\left(\boldsymbol{r}, \tau, \boldsymbol{r}^{*}, \tau^{*}\right)\right), \tilde{p}^{w}\left(\boldsymbol{r}, \tau, \boldsymbol{r}^{*}, \tau^{*}\right)\right)$ taking $\boldsymbol{r}$ and $\tau$ as given. 
At an interior solution, the resulting Nash equilibrium choices are defined by the first-order conditions:

$$
W_{r_{i}} \times\left(\frac{1}{\partial \tilde{p}^{w} / \partial r_{i}}\right)=-\left[\tau W_{p}+W_{\hat{p}^{w}}\right] \text { for } i=1,2, \ldots, R
$$

$$
W_{p}+\theta W_{\tilde{p}^{w}}=0
$$

$$
W_{r_{i}^{*}}^{*} \times\left(\frac{1}{\partial \tilde{p}^{w} / \partial r_{i}^{*}}\right)=-\left[\frac{1}{\tau^{*}} W_{p^{*}}^{*}+W_{\tilde{p}^{w}}^{*}\right] \text { for } i=1,2, \ldots, R^{*}, \text { and }
$$

$$
W_{p^{*}}^{*}+\theta^{*} W_{\hat{p}^{w}}^{*}=0
$$

where, with the Metzler and Lerner paradoxes ruled out,

$$
\theta \equiv \frac{\left[\partial \tilde{p}^{w} / \partial \tau\right]}{[d p / d \tau]}<0 ; \quad \theta^{*} \equiv \frac{\left[\partial \tilde{p}^{w} / \partial \tau^{*}\right]}{\left[d p^{*} / d \tau^{*}\right]}<0
$$

The home government reaction curves are defined by (5) and (6), while the foreign government reaction curves are defined by (7) and (8), with the Nash equilibrium policy choices defined by the joint solutions to these equations.

\section{II.3: Efficient Policies}

We next characterize efficient policy choices. Any efficient combination of policies will achieve the maximal level of welfare for the home government given any fixed level of welfare for the foreign government. The set of efficient policy combinations is defined as the set of solutions to the first order conditions associated with this maximization problem, which with some manipulation can be represented as:

$$
W_{r_{i}} \times\left(\frac{1}{\partial \tilde{p}^{w} / \partial r_{i}}\right)=W_{p} \times\left(\frac{\tilde{p}^{w}}{\partial \tilde{p}^{w} / \partial \tau}\right) \text { for } i=1,2, \ldots, R,
$$

$$
W_{r_{i}^{*}}^{*} \times\left(\frac{1}{\partial \tilde{p}^{w} / \partial r_{i}^{*}}\right)=W_{p^{*}}^{*} \times\left(\frac{-p^{*} / \tau^{*}}{\partial \tilde{p}^{w} / \partial \tau^{*}}\right) \text { for } i=1,2, \ldots, R^{*}, \text { and }
$$




$$
\left(1-A W_{p}\right)=\frac{1}{\left(1-A^{*} W_{p^{*}}^{*}\right)},
$$

where $A \equiv(1-\tau \theta) /\left(W_{p}+\theta W_{\tilde{p}^{w}}\right)$ and $A^{*} \equiv\left(1-\theta^{*} / \tau^{*}\right) /\left(W_{p^{*}}^{*}+\theta^{*} W_{\tilde{p}^{w}}^{*}\right)$.

Here we simply observe that one efficient solution is what we have previously (Bagwell and Staiger, 2001) called the politically optimal solution, defined by

$$
W_{p}=0=W_{p^{*}}^{*} ; W_{r_{i}}=0 \text { for } i=1,2, \ldots, R ; \text { and } W_{r_{i}^{*}}^{*}=0 \text { for } i=1,2, \ldots, R^{*}
$$

\section{National Sovereignty without International Agreements}

We are now ready to consider formally the issue of national sovereignty. To begin, we need to define what we mean by national sovereignty.

\section{III.1: Sovereignty Defined}

An obvious feature of sovereignty is the possession of the sole decision-making authority in determining one's policies. If the level of a policy instrument is directly negotiated between or among governments, it seems reasonable to conclude that national sovereignty over that policy instrument has been lost, at least as long as the agreement is in force. ${ }^{2}$ A definition of sovereignty should reflect this feature.

But beyond this, it also seems that national sovereignty over a set of policy instruments might be threatened indirectly even when direct authority over the setting of those policy instruments remains in the hands of a national government. This threat is emphasized by Rabkin (1998), who observes:

"If sovereignty is defined as the ultimate authority to reject outside control, then all talk of threats to American

\footnotetext{
${ }^{2}$ Even here it can be argued that national sovereignty is preserved provided that the ultimate decision to leave the agreement remains in the hands of a national government. While acknowledging that such ambiguities exist in any discussion of national sovereignty, we nevertheless abstract from a number of these to focus analytically on what we believe are the most important features.
} 
sovereignty may appear quite absurd, especially while America remains the world's only superpower. But that is...an extremely crude way of viewing the question of sovereignty.

"The real threat is not that the United States will be forced to act against the determined resolve of the American political system. Rather, the threat is that international commitments will distort or derange the normal workings of our own system, leaving it less able to resolve policy disputes in ways acceptable to the American people." Rabkin (1998, p. 34).

For example, as a result of an international agreement, a government might be compelled to abide by a set of rules when setting its policies, even though the government may retain control over its own policy choices within the limits dictated by these rules. The MFN rule by which governments agree to abide when they join the GATT/WTO is an example of this kind of restraint in the context of the "unbound" tariff choices of a member government. More subtle is the possibility that international agreements over certain policies could have the effect of eroding the sovereignty of national choices over other "domestic" policies. The notion that GATT/WTO tariff commitments may be fueling a "race to the bottom" in domestic regulatory policies reflects this kind of possibility.

Moreover, even absent international agreements, a government may feel constrained by the unilateral policy choices of other governments. In this regard, a government might feel that the choices it has available to it for imposing costly regulations on its export industries are constrained by the unilateral policy choices of governments in other countries whose export industries compete for world markets. More generally, governments may consider it to be a loss of national sovereignty when the "discipline" imposed by international markets constrains their options. This point is often made in the context of international capital flows, but the logic can be equally applied to comparative-advantage based changes in the location of global production that occur even when factors of production are themselves internationally immobile. In effect, governments use policies to induce outcomes over things they care about, and the policy choices of one government may constrain the possible outcomes that another government's policy choices can induce, even if there is no international agreement between the two governments.

As this discussion indicates, defining sovereignty is not a simple task. In fact, Krasner (2001) identifies four distinct ways in which the term "sovereignty" has been commonly used in the 
international political science literature. Krasner refers to these as domestic sovereignty, international legal sovereignty, interdependence sovereignty, and Westphalian sovereignty. Domestic sovereignty refers to the organization and effectiveness of political authority within the state. International legal sovereignty refers to the mutual recognition of states. Interdependence sovereignty refers to the scope of activities over which states can effectively exercise unilateral control. And Westphalian sovereignty reflects as its central premise the rule of nonintervention in the internal affairs of other states.

In principle, international agreements could have important implications for any of these four notions of sovereignty. Nevertheless, we will focus our analytical work on the implications of international agreements for interdependence sovereignty and Westphalian sovereignty, as these notions seem most closely related to the issues at the heart of our discussion above.

To try to capture these features of national sovereignty, we propose the following definitions. In essence, we associate with interdependence sovereignty the notion of unilateral control, and with Westphalian sovereignty the notion of internal affairs:

Definition: A government exercises unilateral control in a choice problem provided that its payoff in that choice problem is unaffected by the choices of other governments. A government has interdependence sovereignty in any choice problem within which it exercises unilateral control.

Definition: A government's choice problem concerns its internal affairs provided that all other governments are indifferent to the outcome of that choice problem. A government has Westphalian sovereignty in any choice problem that concerns its internal affairs.

Definition: A government has sovereignty in any choice problem for which it has both interdependence and Westphalian sovereignty.

Admittedly, while these definitions have the advantage of analytical clarity, they do not capture the breadth of concerns that are embodied in the conventional usage of these notions of sovereignty in the political science and legal literature. This is perhaps particularly true of our 
definition of Westphalian sovereignty. For example, as Krasner (2001) observes, Vattel was one of the first writers to explicitly articulate the principle of nonintervention, from which the notion of Westphalian sovereignty developed. ${ }^{3}$ Vattel (1872, pp. 59-60) draws a distinction between "perfect rights and obligations," which are associated with "the right of compulsion," and "imperfect rights and obligations," which are associated only with "the right to ask." Using this distinction, Vattel associates a nation's internal affairs with any choice that does not affect the perfect rights of any other nation. Moreover, Vattel (1872, pp. 226-227) asserts that the rights and obligations stemming from trade with other nations are imperfect. Accordingly, as long as they are voluntary (reflecting only "the right to ask"), commercial treaties between nations would not ordinarily be viewed as violating Westphalian sovereignty, unless these treaties impaired the perfect rights of some nation.

As this discussion suggests and as much of the legal and political science literature reflects, violations of Westphalian sovereignty are commonly associated with coercion, which is not really our concern here. Nevertheless, Westphalian sovereignty can be compromised through invitation (voluntary action) as well as intervention (coercion). As Krasner (2001) notes:

“...Rulers may issue invitations for a variety of reasons, including tying the hands of their successors, securing external financial resources, and strengthening domestic support for values that they, themselves, embrace. Invitations may sometimes be inadvertent; rulers might not realize that entering into an agreement may alter their own domestic institutional arrangements. Regardless of the motivation or the perspicacity of rulers, invitations violate Westphalian sovereignty by subjecting internal authority structures to external constraints...” Krasner (2001, p. 22).

We may think of the notion of internal affairs offered above - from which we define Westphalian sovereignty - as particularly useful for assessing when Westphalian sovereignty might be compromised through invitation (e.g., through a voluntary international agreement). That is, as we discuss further below, if an international agreement impinges on the choices a government makes even when those choices are a matter of indifference to foreign governments, i.e., its "internal affairs," then it seems natural to conclude that this government's Westphalian sovereignty has been compromised. In this way, we believe that our definitions of (Westphalian and interdependence) sovereignty, while not always consistent with the conventional usage of these terms, do capture key

\footnotetext{
${ }^{3}$ In this regard, Krasner (2001, p. 20) notes that the common terminology of "Westphalian sovereignty" actually reflects a historical inaccuracy, since the "...norm of nonintervention in internal affairs had virtually nothing to do with the Peace of Westphalia...".
} 
elements of the nature of sovereignty as it relates to concerns over international agreements.

In the remainder of the paper, we will explore the nature of national sovereignty in various international settings using the definitions above. In each case, we evaluate the degree of sovereignty according to a local criterion, by asking what degree of sovereignty is present for small policy changes around an equilibrium.

\section{III.2: Sovereignty in the Absence of International Agreements}

With sovereignty defined, we next characterize the nature and degree of sovereignty possessed by each government in the Nash Policy Game. This provides an important benchmark, because the impact of an international agreement on a nation's sovereignty can only be assessed once the nature and degree of sovereignty absent the agreement is understood. The sovereignty possessed by a government in the Nash Policy Game thus provides a natural baseline from which to gauge the impact of any international agreement.

Our approach is to propose a particular partition of a government's best-response choice problem into an equivalent problem in which two sub-problems are solved sequentially, and then to show that the government enjoys sovereignty over the choices it faces in the first-step subproblem, but that it (generally) does not have sovereignty over the choices it faces in the second-step sub-problem. Our argument is then completed by establishing that the second-step choices that the government faces in this particular partition are also necessary in any other partition that produces sovereign choices in the associated first-step sub-problem. With this established, we may conclude that our proposed partition identifies the maximal sovereign choice set for each government in the Nash Policy Game. As a consequence of this argument, we thus establish that a government's sovereign choices in the Nash Policy Game are the choices it makes in the first-step sub-problem of our chosen partition.

We develop this partition from the perspective of the domestic government (an analogous development holds for the foreign government). To this end, recall the best-response policy choice 
problem of the domestic government, defined by Program 1 in the previous section. Using the market-clearing condition (3) that determines $\tilde{p}^{w}$, Program 1 (which takes $\boldsymbol{r}^{*}$ and $\tau^{*}$ as given) can be equivalently written as

$$
\begin{aligned}
& \operatorname{Max}_{\boldsymbol{r}, \tau, \tilde{p}^{w}} W\left(\boldsymbol{r}, p\left(\tau, \tilde{p}^{w}\right), \tilde{p}^{w}\right) \\
& \text { s.t. } \quad M\left(\boldsymbol{r}, p\left(\tau, \tilde{p}^{w}\right), \tilde{p}^{w}\right)-E^{*}\left(\boldsymbol{r}^{*}, p^{*}\left(\tau^{*}, \tilde{p}^{w}\right), \tilde{p}^{w}\right)=0,
\end{aligned}
$$

which is in turn equivalent to

$$
\begin{aligned}
& \operatorname{Max}_{\boldsymbol{r}, \tau, \tilde{p}^{w}} \quad W\left(\boldsymbol{r}, p\left(\tau, \tilde{p}^{w}\right), \tilde{p}^{w}\right) \\
& \text { s.t. } \quad\left[M\left(\boldsymbol{r}, p\left(\tau, \tilde{p}^{w}\right), \tilde{p}^{w}\right)-M\right]+\left[M-E^{*}\left(\boldsymbol{r}^{*}, p^{*}\left(\tau^{*}, \tilde{p}^{w}\right), \tilde{p}^{w}\right)\right]=0
\end{aligned}
$$

for any $M$.

Consider now the partition of this program into the alternative two-step program:

Program 1': Step 1. Fix $\left(M, \tilde{p}^{w}\right)$, and Max $x_{r, \tau} W\left(\boldsymbol{r}, p\left(\tau, \tilde{p}^{w}\right), \tilde{p}^{w}\right)$

$$
\text { s.t. } \quad\left[M\left(\boldsymbol{r}, p\left(\tau, \tilde{p}^{w}\right), \tilde{p}^{w}\right)-M\right]=0 .
$$

$$
\begin{aligned}
& \text { Step 2. } \operatorname{Max} \text { M, } \tilde{p}^{w} \quad L\left(\boldsymbol{r}\left(M, \tilde{p}^{w}\right), p\left(\tau\left(M, \tilde{p}^{w}\right), \tilde{p}^{w}\right), M, \tilde{p}^{w}\right) \\
& \text { s.t. } \quad\left[M-E^{*}\left(\boldsymbol{r}^{*}, p^{*}\left(\tau^{*}, \tilde{p}^{w}\right), \tilde{p}^{w}\right)\right]=0,
\end{aligned}
$$

where $\boldsymbol{r}\left(M, \tilde{p}^{w}\right)$ and $\tau\left(M, \tilde{p}^{w}\right)$ are the solutions from Step 1 and $L$ is the Step-1 Lagrangean. ${ }^{4}$ For future reference, we denote by $G$ the Lagrangean associated with the Step-2 sub-problem.

The two-step partition defined in Program 1' may be interpreted as follows. Following Bagwell and Staiger (2001), we define the level of market access as the volume of imports a country

\footnotetext{
${ }^{4}$ Program 1' abuses notation slightly. In the program, $\tilde{p}^{w}$ is a number, which is constrained ultimately to correspond to the $\tilde{p}^{w}$ function defined by (3).
} 
would accept at a particular world price. Accordingly, the Step-1 choice problem in Program 1' describes the domestic government's choice of tariff and regulatory policies among the feasible domestic policy combinations defined by the domestic market-access constraint for any given level of domestic market access, i.e., among the feasible domestic policy combinations $(\boldsymbol{r}, \tau)$ defined by $\left[M\left(\boldsymbol{r}, p\left(\tau, \tilde{p}^{w}\right), \tilde{p}^{w}\right)-M\right]=0$ for any $\left(M, \tilde{p}^{w}\right)$. The Step-2 choice problem in Program 1' then describes the domestic government's choice of a particular domestic market access level among the feasible domestic market access levels defined by the foreign export supply curve for any given level of foreign policies and the requirement of market clearing, i.e., among the feasible domestic market access levels $\left(M, \tilde{p}^{w}\right)$ defined by the constraint $\left[M-E^{*}\left(\boldsymbol{r}^{*}, p^{*}\left(\tau^{*}, \tilde{p}^{w}\right), \tilde{p}^{w}\right)\right]=0$ for any $\left(\boldsymbol{r}^{*}, \tau^{*}\right)$.

To establish that Program 1 and Program 1' are equivalent ways of expressing the domestic government's best-response policy choice problem, we first record the first-order conditions that define the solutions to the Step-1 and Step-2 sub-problems of Program 1'. Using the Envelope Theorem, and with $\lambda$ denoting the Lagrange multiplier associated with $L$ and $\gamma$ denoting the Lagrange multiplier associated with $G$, the first-order conditions associated with the domestic government's Step-1 sub-program are

$$
\begin{aligned}
& W_{r_{i}}+\lambda M_{r_{i}}=0 \text { for } i=1,2, \ldots, R, \text { and } \\
& W_{p}+\lambda M_{p}=0
\end{aligned}
$$

while the first-order conditions associated with the domestic government's Step-2 sub-program are then

$$
\begin{aligned}
& \frac{\partial G}{\partial M}=-\lambda+\gamma=0, \text { and } \\
& \frac{\partial G}{\partial \hat{p}^{w}}=\left[\tau W_{p}+W_{\hat{p}^{w}}\right]+\lambda\left[\tau M_{p}+M_{p^{w}}\right]-\gamma\left[\frac{1}{\tau^{*}} E_{p^{*}}^{*}+E_{p^{w}}^{*}\right]=0 .
\end{aligned}
$$

We may now state: 
Lemma 1: Program 1 and Program 1' are equivalent ways of characterizing the domestic government's best-response policies for any $\boldsymbol{r}^{*}$ and $\tau^{*}$.

Proof: See Appendix.

We prove Lemma 1 by establishing that the first-order conditions associated with Program 1', (13)(16), are equivalent to the first-order conditions associated with Program 1, (5)-(6).

In light of Lemma 1, we next characterize the degree of sovereignty that the domestic government enjoys in the Nash Policy Game when sovereignty is evaluated using the particular partition of the domestic government's best-response choice problem described by Program 1'. While a completely analogous result to Lemma 1 may be stated for the foreign government, we continue to focus on the domestic government, and begin with its Step-1 choices.

In Step 1 of Program 1', the levels of $M$ and $\tilde{p}^{w}$ are taken as fixed, because they are determined by the domestic government in its Step-2 sub-problem. Hence, the domestic government exercises unilateral control in its Step 1 choice problem since, with $M$ and $\tilde{p}^{w}$ given, its payoff in that choice problem is unaffected by the choices of the foreign government. ${ }^{5}$ Accordingly, the domestic government has interdependence sovereignty in its Step-1 choice problem. Moreover, the Step-1 choice problem of the domestic government concerns its internal affairs since, with $M$ and $\tilde{p}^{w}$ determined in its Step-2 sub-problem, the foreign government is indifferent to the outcome of the domestic government's Step-1 choice problem. ${ }^{6}$ Accordingly, we may conclude that the domestic government has Westphalian sovereignty in its Step-1 choice problem as well.

Exactly analogous observations hold for the foreign government's Step-1 choice problem.

\footnotetext{
${ }^{5}$ Of course, different levels of $r^{*}$ and $\tau^{*}$ may lead to different choices of $M$ and $\tilde{p}^{w}$, but the point is that these choices are made by the domestic government in Step 2, and therefore $M$ and $\tilde{p}^{w}$ are taken as fixed in Step 1.

${ }^{6}$ That is, for given $r^{*}$ and $\tau^{*}$, the foreign government is indifferent over combinations of $\boldsymbol{r}$ and $\tau$ that deliver the same $M$ and hence $\tilde{p}^{w}$ (by the requirement of market clearing given by $\left[M-E^{*}\left(\boldsymbol{r}^{*}, p^{*}\left(\tau^{*}, \tilde{p}^{w}\right), \tilde{p}^{w}\right)\right]=0$ ), as indicated by its implied welfare level $W^{*}\left(\boldsymbol{r}^{*}, p^{*}\left(\tau^{*}, \tilde{p}^{w}\right), \tilde{p}^{w}\right)$.
} 
Let us denote by $\boldsymbol{r}^{*}\left(M^{*}, \tilde{p}^{w}\right)$ and $\tau^{*}\left(M^{*}, \tilde{p}^{w}\right)$ the solutions from the foreign government's analogous Step-1 problem. Finally, we denote by $\boldsymbol{I}\left(M, \tilde{p}^{w}\right)$ the (length $\left.R+1\right)$ vector of domestic policy instruments chosen by the domestic government in its Step-1 problem, and similarly we denote by $\boldsymbol{I}^{*}\left(M^{*}, \tilde{p}^{w}\right)$ the (length $\left.R^{*}+1\right)$ vector of foreign policy instruments chosen by the foreign government in its Step-1 problem. We may now state:

Proposition 1: When evaluated using the partition described in Program 1', each government's choice of how best to use its policy instruments to achieve its objectives while delivering any level of market access (i.e, the function $I\left(M, \tilde{p}^{w}\right)$ for the domestic government and the function $\boldsymbol{I}^{*}\left(M^{*}, \tilde{p}^{w}\right)$ for the foreign government) is sovereign in the Nash Policy Game.

Consider next the domestic government's Step-2 choices. The foreign government's policy choices influence the domestic government's payoff in this choice problem through the constraint in the domestic government's Step-2 program. As a consequence, the domestic government exercises unilateral control in its Step-2 choice problem if and only if the multiplier on this constraint, $\gamma$, is zero. In addition, the foreign government is indifferent to the outcome of the domestic government's Step-2 choice problem - and therefore this choice problem concerns the domestic government's internal affairs - if and only if the foreign government is indifferent to changes in the world price (i.e., $W_{\tilde{p}^{w}}^{*}=0$ ). In general, neither of these conditions will hold in our two-country model, and so in general each government will enjoy neither interdependence sovereignty nor Westphalian sovereignty in its Step-2 choice problem. ${ }^{7}$

As a general matter, then, Proposition 1 provides the full characterization of the degree of sovereignty enjoyed by governments in the Nash Policy Game when evaluated using the partition described in Program 1'. However, there is one special case where governments do enjoy some sovereignty in their Step-2 choices, and in this case it turns out that they enjoy both interdependence

\footnotetext{
${ }^{7}$ We consider how these statements must be modified to accommodate the possibility of "small" countries in section $\mathrm{V}$, where we develop a many country model.
} 
and Westphalian sovereignty in their Step-2 choices. To describe this special case, we say that a government has absolute sovereignty if it has sovereignty in all its choice problems. ${ }^{8}$ In light of Proposition 1, we may now characterize this case as follows:

Proposition 2: When evaluated using the partition described in Program 1', governments enjoy absolute sovereignty in the Nash Policy Game if and only if the politically optimal choices of tariffs and standards imply autarky.

Proof: To prove this proposition, we need only (in light of Proposition 1) establish that the Step-2 choice problem of each government is sovereign if and only if the politically optimal choices of tariffs and standards imply autarky. We consider the home government, and recall that sovereignty in its Step-2 choice problem arises if and only if (i) $\gamma=0$, and (ii) $W_{\tilde{p}^{w}}^{*}=0$. Using (13)-(16), we may derive the following three expressions for $\gamma$ :

$$
\gamma=-\frac{W_{r_{i}}}{M_{r_{i}}} \text { for } i=1,2, \ldots, R
$$

$$
\gamma=-\frac{W_{p}}{M_{p}} ; \text { and }
$$

$$
\gamma=\frac{\tau W_{p}+W_{\tilde{p}^{w}}}{\left[\left(\frac{1}{\tau^{*}} E_{p^{*}}^{*}+E_{p^{w}}^{*}\right)-\left(\tau M_{p}+M_{p^{w}}\right)\right]}
$$

By (17a)-(17c), (12) and (4a), $\gamma=0$ if and only if the politically optimal choices of tariffs and standards imply autarky, which by (4a) implies as well that $W_{\tilde{p}^{w}}^{*}=0$. An analogous argument applies to the foreign government.

\section{QED}

As politically optimal policy choices are efficient, an immediate implication of Proposition

\footnotetext{
${ }^{8}$ Strictly speaking, this definition should be stated for a particular partition of the government choice problem, so that the statement "all its choice problems" has an exact meaning. However, as becomes clear from Proposition 2, if a government has absolute sovereignty under any partition of its choices, then it has absolute sovereignty under every partition of its choices, and so we prefer to keep the definition of absolute sovereignty provided in the text more informal.
} 
2 is the following:

Corollary: When evaluated using the partition described in Program 1', policy choices in the Nash Policy Game are absolutely sovereign if and only if they are also efficient.

Hence, as Proposition 2 and its Corollary indicate, when evaluated using the partition described in Program 1', absolute sovereignty is achievable in the absence of international agreements only when (i) countries are in absolute isolation, and (ii) this isolation is internationally efficient, and so there is no reason for the existence of international agreements.

Together, Propositions 1 and 2 imply that, when evaluated using the partition described in Program 1', the sovereign choices of each government in the Nash Policy Game (outside the absolute-isolation benchmark) are described by the respective functions $\boldsymbol{I}\left(M, \tilde{p}^{w}\right)$ and $\boldsymbol{I}^{*}\left(M^{*}, \tilde{p}^{w}\right)$. In effect, in the Nash Policy Game each government maintains sovereignty over all choices other than its market access choices: but governments enjoy neither Westphalian nor interdependence sovereignty over their market access choices, despite the fact that there is no international agreement in the Nash Policy Game. Of course, this characterization of sovereignty depends upon the particular (and potentially arbitrary) partition described in Program 1'. However, we next suggest that this partition provides a sensible basis from which to characterize sovereignty in the Nash Policy Game, because the constraints imposed in Step 1 under this partition are a subset of the constraints imposed in Step 1 under any other partition that yields sovereign Step-1 choices. As a consequence, the partition described in Program 1' may be said to identify the maximal sovereign choice set for each government in the Nash Policy Game.

More specifically, we now turn to the final step of our argument, and establish that the second-step choices that the government faces in the partition defined in Program 1' are also necessary in any other partition that produces sovereign choices in the associated first-step subproblem. The only exception to this statement arises in the absolute-isolation benchmark case identified in Proposition 2, where governments enjoy absolute sovereignty in the Nash Policy Game when evaluated using the partition described in Program 1': in that case, any partition of the 
government's best-response choice problem will yield the same characterization of sovereignty. We record this finding in:

Lemma 2: If a partition of the domestic (foreign) government's best-response choice problem contains a sub-problem within which the domestic (foreign) government's choices are sovereign, then the level of domestic (foreign) market access must be determined by domestic (foreign) choices outside of this sub-problem, unless governments enjoy absolute sovereignty in the Nash Policy Game.

Proof: Consider the domestic government. Suppose that, under a certain partition of the government's best-response choice problem, there exists a sub-problem within which the domestic government's choices are sovereign. If the level of domestic market access is not determined by the domestic government's choices outside of this sub-problem, then the level of domestic market access must be determined (fixing the choices in all its other sub-problems) by the domestic government's choices in this sub-problem. In this sub-problem, then, the domestic government must (i) make choices which determine the market-clearing world price $\tilde{p}^{w}$, and (ii) face the constraint (possibly among multiple constraints) on feasible domestic market access levels defined by the foreign export supply curve and the requirement of market clearing, i.e., $\left[M-E^{*}\left(\boldsymbol{r}^{*}, p^{*}\left(\tau^{*}, \tilde{p}^{w}\right), \tilde{p}^{w}\right)\right]=0$. But unless governments enjoy absolute sovereignty in the Nash Policy Game, Westphalian sovereignty is precluded by (i), while interdependence sovereignty is precluded by (ii), contradicting the original supposition that the domestic government's choices are sovereign in this sub-problem. Therefore, the level of domestic market access must be determined by choices outside of this sub-problem, unless governments enjoy absolute sovereignty in the Nash Policy Game.

\section{QED}

According to Lemma 2, as long as attention is restricted to settings in which absolute isolation is not efficient - a restriction we maintain from here on - then the partition of the domestic government's best-response policy choices described in Program 1' identifies the maximal sovereign choice set over all possible partitions of the domestic government's best-response policy choices: as described by the unilateral choice function $I\left(M_{,} \tilde{p}^{w}\right)$, the choices that the domestic government makes over its maximal sovereign choice set concern everything that it cares about except the level 
of market access it affords to the foreign country. Lemma 2 implies that any other sovereign choice set associated with any other partition of the government's best-response policy choices must also exclude market access (and if different from the maximal sovereign choice set described by Program 1 , must exclude other choices as well). With analogous observations for the foreign government, we may therefore state:

Proposition 3: The unilateral choice functions $\boldsymbol{I}\left(M, \tilde{p}^{w}\right)$ and $\boldsymbol{I}^{*}\left(M^{*}, \tilde{p}^{w}\right)$ describe, respectively, the choices that the domestic and foreign government make over their maximal sovereign choice sets in the Nash Policy Game.

Armed with Proposition 3, we now associate the domestic and foreign government's sovereign choices in the Nash Policy Game - henceforth their sovereign choices - with the respective unilateral choice functions $\boldsymbol{I}\left(M, \tilde{p}^{w}\right)$ and $\boldsymbol{I}^{*}\left(M^{*}, \tilde{p}^{w}\right)$. In the following section, we use these functions to evaluate the erosion of national sovereignty that may occur once governments negotiate international agreements. ${ }^{9}$

\section{National Sovereignty and International Trade Agreements}

In this section we explore the ways in which international trade agreements may erode national sovereignty. We have argued in the previous section that the sovereign choices of the domestic and foreign governments absent any international agreement are represented by the respective unilateral choice functions $\boldsymbol{I}\left(M, \tilde{p}^{w}\right)$ and $\boldsymbol{I}^{*}\left(M^{*}, \tilde{p}^{w}\right)$. Our central concern, then, is whether an international trade agreement has the effect of "corrupting" (i.e., altering) these choice functions with external influence. This concern provides one way to formalize the threat described by Rabkin (1998, p. 34) and quoted in section III.1 above, that “...international commitments will

\footnotetext{
${ }^{9}$ Recalling now our discussion of sovereignty in section III.1, a link can be forged between the sovereign choice functions defined by $I\left(M, \tilde{p}^{w}\right)$ and $I^{*}\left(M^{*}, \tilde{p}^{w}\right)$ and the notion of Westphalian sovereignty described in the passage quoted from Krasner (2001). We may think of alterations in these functions which arise as a result of international agreements as analogous to alterations in the "domestic institutional arrangements" that these agreements might trigger. The link is not exact, however, as the functions $I\left(M, \tilde{p}^{w}\right)$ and $I^{*}\left(M^{*}, \tilde{p}^{w}\right)$ reflect choices that feature interdependence (as well as Westphalian) sovereignty.
} 
distort or derange the normal workings of our own system, leaving it less able to resolve policy disputes in ways acceptable to the American people." (see also note 9).

As discussed in section III.1, international agreements may encroach on national sovereignty both directly and indirectly. We say that the domestic (foreign) government's sovereignty over a policy instrument in $I \quad\left(I^{*}\right)$ is directly compromised by an international agreement whenever limits on this policy instrument are determined directly as a result of international negotiations. We say that a government's sovereignty is indirectly compromised by an international agreement whenever there exists a policy instrument for which the government's sovereignty is not directly compromised by the international agreement but for which the government's unilateral choice differs from its sovereign choice (i.e., differs from the corresponding element of $\boldsymbol{I}\left(M, \tilde{p}^{w}\right)$-for the domestic government - or $\boldsymbol{I}^{*}\left(M^{*}, \tilde{p}^{w}\right)$ - for the foreign government) evaluated at the level of market access delivered under the agreement. Finally, we say that a government's sovereignty over a policy instrument is compromised (preserved) whenever its sovereignty is directly or indirectly (neither directly nor indirectly) compromised.

Consider first an international trade agreement that specifies the tariff levels to be applied by each government and also possibly the regulatory levels for a subset of domestic regulations and a subset of foreign regulations. Let the domestic regulations that are not determined directly by the international agreement be contained in the set $H$, and let the foreign regulations that are not determined directly by the international agreement be contained in the set $H^{*}$. If the international trade agreement concerns only tariff levels, then the set $H$ contains the entire vector of domestic regulations $\boldsymbol{r}$ and the set $H^{*}$ contains the entire vector of foreign regulations $\boldsymbol{r}^{*}$. Otherwise, these sets contain only a subset of the elements of the respective regulatory vectors.

At this point it proves convenient to introduce a notion of "interrelatedness" between policies. Taking the perspective of the domestic government, and recalling that $L$ denotes the Step- 1 Lagrangean for Program 1, we say that two policies $u$ and $v$ are interrelated if $L_{u v} \neq 0$ when $L$ is 
evaluated at the maximized Step-1 choices $\boldsymbol{I}\left(M, \tilde{p}^{w}\right)$. In words, when $u$ and $v$ are interrelated, a change in $v$ alters the level of $u$ preferred by the domestic government for delivering a given level of market access. An exactly analogous interpretation applies for the foreign government.

We may now state:

Proposition 4: An international trade agreement that specifies levels for domestic and foreign tariffs and a subset of domestic and foreign regulations must, for each government, compromise that government's sovereignty over at least as many policy instruments as it preserves, provided that: (i) the agreement specifies at least one policy instrument for each government at a level different from its best-response level; and (ii) all policies are interrelated.

Proof: We adopt the perspective of the domestic government. If $H$ is empty, then it is immediate that the statement of the proposition is satisfied, since in this case the sovereignty over all domestic instruments is (directly) compromised. If instead $H$ is non-empty, then the proposition is proved if it can be established that, to preserve the sovereignty of $m$ domestic policy instruments, at least $m$ domestic policy instruments must be directly negotiated (and therefore the domestic government's sovereignty over these instruments is directly compromised). Let $\boldsymbol{h}$ be the vector of domestic regulatory choices under the domestic government's control, and let $\bar{\tau}$ be the domestic tariff level and $\bar{n}$ be the vector of domestic regulations specified by the international trade agreement. Given any foreign policies $\boldsymbol{r}^{*}$ and $\tau^{*}$, the domestic government's unilateral best-response choice of $\boldsymbol{h}$ must solve the program:

Program 2: $\quad \operatorname{Max}_{\boldsymbol{h}} W\left(\boldsymbol{h}, \overline{\boldsymbol{n}}, p\left(\bar{\tau}, \tilde{p}^{w}\left(\boldsymbol{h}, \overline{\boldsymbol{n}}, \bar{\tau}, \boldsymbol{r}^{*}, \tau^{*}\right)\right), \tilde{p}^{w}\left(\boldsymbol{h}, \overline{\boldsymbol{n}}, \bar{\tau}, \boldsymbol{r}^{*}, \tau^{*}\right)\right)$

taking $\tau^{*}$ and $\boldsymbol{r}^{*}$ as given. The first-order conditions for Program 2 are given by the analogue of (5) for the domestic regulatory choices contained in $H$. Now consider the partition of this program into the alternative two-step program:

Program 2': Step 1: Fix $\left(M, \tilde{p}^{w}\right)$, and Max ${ }_{\boldsymbol{h}} \quad W\left(\boldsymbol{h}, \overline{\boldsymbol{n}}, p\left(\bar{\tau}, \tilde{p}^{w}\right), \tilde{p}^{w}\right)$

$$
\text { s.t. }\left[M\left(\boldsymbol{h}, \overline{\boldsymbol{n}}, p\left(\bar{\tau}, \tilde{p}^{w}\right), \tilde{p}^{w}\right)-M\right]=0 .
$$




$$
\begin{aligned}
& \text { Step 2: } \quad \operatorname{Max}_{M, \tilde{p}^{w}} \quad Q\left(\boldsymbol{h}\left(M, \tilde{p}^{w} ; \bar{n}, \bar{\tau}\right), \overline{\boldsymbol{n}}, p\left(\bar{\tau}, \tilde{p}^{w}\right), M, \tilde{p}^{w}\right) \\
& \text { s.t. } \quad\left[M-E^{*}\left(\boldsymbol{r}^{*}, p^{*}\left(\tau^{*}, \tilde{p}^{w}\right), \tilde{p}^{w}\right)\right]=0,
\end{aligned}
$$

where $\boldsymbol{h}\left(M, \tilde{p}^{w} ; \bar{n}, \bar{\tau}\right)$ is the solution from Step 1 and solves the first-order conditions analogous to (13) for the domestic regulatory choices contained in $H$, and $Q$ is the Step-1 Lagrangean. Arguments identical to those in the proof of Lemma 1establish that Program 2 and Program 2' are equivalent ways of characterizing the domestic government's unilateral best-response choice of $\boldsymbol{h}$. Hence, to complete the proof we need only observe that: (a) preserving the sovereignty of $m$ domestic policy instruments requires that, with market access fixed at the level delivered under the agreement, it must be possible to satisfy the Step-1 first-order conditions when evaluated at the corresponding $m$ elements of $\boldsymbol{I}\left(M, \tilde{p}^{w}\right)$, with $\boldsymbol{I}\left(M, \tilde{p}^{w}\right)$ itself evaluated at the level of market access delivered under the agreement; and (b) with all policies interrelated, this in turn requires that there exist at least $m$ policy instruments that are directly negotiated and can be used to "target" $m$ of these Step-1 first-order conditions. The only exception to this requirement occurs if the agreement fails to specify at least one policy instrument for each government at a level different from its best-response level, an exception that is ruled out by the conditions of the proposition. An analogous argument applies to the foreign government.

\section{QED}

According to Proposition 4, any international trade agreement that moves a government away from its unilateral best-response policies by specifying permissible levels for a subset of that government's policies must compromise that government's sovereignty over at least as many instruments as it preserves, provided only that its policies are interrelated. This seems to suggest a basic tradeoff that governments must typically confront between international efficiency - which in general cannot be achieved in the absence of an international trade agreement that moves governments away from their unilateral best-response policies - and national sovereignty. However, the existence of this tradeoff is not inevitable. As we next show, an international agreement can be designed in such a way as to avoid the need to sacrifice national sovereignty in pursuit of international efficiency. 
To establish this, we will say that a government's sovereignty is preserved by an international agreement if its sovereignty over every policy instrument is preserved (i.e., is neither directly nor indirectly compromised). Consider, then, the following market access agreement. Under a market access agreement, the domestic government agrees to abide by a specified domestic market access constraint defined by a level of domestic import volume $\bar{M}$ and world price level $\bar{p}^{w}$, $M\left(r, p\left(\tau, \bar{p}^{w}\right), \bar{p}^{w}\right)=\bar{M}$, but the domestic government is otherwise free to choose its tariff $\tau$ and domestic regulations $\boldsymbol{r}$. Similarly, the foreign government agrees to abide by a specified foreign market access constraint defined by a level of foreign import volume $\bar{M}^{*}$ and world price level $\bar{p}^{w}$, $M^{*}\left(\boldsymbol{r}^{*}, p^{*}\left(\tau^{*}, \bar{p}^{w}\right), \bar{p}^{w}\right)=\bar{M}^{*}$, but the foreign government is otherwise free to choose its tariff $\tau^{*}$ and foreign regulations $\boldsymbol{r}^{*}$. Notice that a market access agreement has the domestic and foreign governments making joint determinations over the magnitudes for which, according to Proposition 3, they each lack sovereignty in the Nash Policy Game (namely, the Step-2 choices of each government), but each government continues to make unilateral choices in a market access agreement over the magnitudes for which it enjoys sovereignty in the Nash Policy Game according to Proposition 3 (namely, the Step-1 choices of each government as embodied in $\mathbf{I}\left(M, \tilde{p}^{w}\right)$ and $\left.\boldsymbol{I}^{*}\left(M^{*}, \tilde{p}^{w}\right)\right)$.

We may now state:

Proposition 5: Market access agreements preserve the sovereignty of each government.

Proof: The proof is immediate, since (i) neither government's sovereignty is directly compromised, and (ii) given its domestic market access constraint the domestic government then chooses $\mathbf{I}\left(\bar{M}_{,} \bar{p}^{w}\right)$, while given its foreign market access constraint the foreign government then chooses $\boldsymbol{I}^{*}\left(\bar{M}^{*}, \bar{p}^{w}\right)$, and so neither government's sovereignty is indirectly compromised.

QED

We have established in Bagwell and Staiger (2001, Proposition 1) that the nature of the international inefficiency in the Nash equilibrium of this model is an insufficient level of market 
access, and it is therefore direct that a market access agreement can achieve international efficiency by expanding market access to an efficient level. As a consequence, we may also state the following:

Corollary: Market access agreements involve no tradeoff between international efficiency and national sovereignty.

\section{National Sovereignty and Non-discrimination}

We now extend the two-country model with standards to a three-country setting. In particular, we introduce a second foreign country, so that the domestic country now has two trading partners. This creates the possibility that the domestic country might set discriminatory tariffs against each of its trading partners, and allows us to consider the implications for national sovereignty of an international agreement to abide by a non-discrimination rule, such as the MFN rule to which governments must adhere when they join the GATT/WTO.$^{10}$ The three-country model is based on the multi-country model in Bagwell and Staiger (1999), adapted to allow for the possibility of both tariff and domestic standards choices.

\section{V.1: The Three-Country Trade Model}

The home country exports good $y$ to foreign countries 1 and 2 in exchange for imports of good $x$ from each of them. For simplicity, we do not allow trade between the two foreign countries, and so only the home country has the opportunity to set discriminatory tariffs across its trading partners. The local relative price of good $x$ to good $y$ in the home country (foreign country $j$ ) is denoted by $p \quad\left(p^{* j}, j=1,2\right)$. The "world price" (i.e., relative exporter price) for trade between the home country and foreign country $j$ is denoted by $p^{w j}$, and international arbitrage links each country's local price to the relevant world price in light of its tariff according to $p=\tau^{j} p^{w j} \equiv p\left(\tau^{j}, p^{w j}\right)$, and $p^{* j}=p^{w j} / \tau^{* j} \equiv p^{* j}\left(\tau^{* j}, p^{w j}\right)$ for $j=1,2$, where $\tau^{j} \quad\left(\tau^{* j}\right)$ is one plus the ad valorem import tariff that the home country (foreign country $j$ ) applies to the imports from foreign country $j$ (the home

\footnotetext{
${ }^{10}$ The other important non-discrimination rule in the GATT/WTO is that of "national treatment," which applies to non-border measures. In our formal model, the MFN rule would apply to tariffs, while the national treatment rule would apply to regulations. We focus here on the implications of the MFN rule for national sovereignty, but analogous findings could be formalized with regard to national treatment.
} 
country). This implies in turn that world prices are linked across bilateral relationships:

$$
p^{w 1}=\left[\tau^{2} / \tau^{1}\right] p^{w 2}
$$

We note in particular that an MFN rule requires $\tau^{1}=\tau^{2}$ and therefore implies $p^{w 1}=p^{w 2} \equiv p^{w}$ by (18). As in the two-country model above, in addition to its tariff, each country also imposes a vector of local regulations, $\boldsymbol{r}$ (with length $R$ ) for the home country and $\boldsymbol{r}^{* \boldsymbol{j}}$ (with length $R^{* j}$ ) for foreign country $j$, that may impact local production and/or consumption decisions at given prices. Each country's vector of local regulations will therefore act as a vector of "shift" parameters in its import demand and export supply functions, and as before we assume that these functions are differentiable in their respective regulation levels.

Incorporating each country's vector of regulations into its import demand and export supply functions, we denote these functions for the home country by $M(\boldsymbol{r}, p, T)$ and $E(\boldsymbol{r}, p, T)$, respectively, and for foreign country $j$ by $M^{* j}\left(\boldsymbol{r}^{* j}, p^{* j}{ }_{9} p^{w j}\right)$ and $E^{* j}\left(\boldsymbol{r}^{* j}{ }_{s} p^{* j}, p^{w j}\right)$, respectively, where $T$ is the home-country's multilateral terms of trade, and is defined by

$$
T\left(\boldsymbol{r}^{* 1}, p^{* 1}, \boldsymbol{r}^{* 2}, p^{* 2}, p^{w 1}, p^{w 2}\right) \equiv \sum_{k=1,2} s^{* k}\left(\boldsymbol{r}^{* 1}, p^{* 1}, \boldsymbol{r}^{* 2}, p^{* 2}, p^{w 1}, p^{w 2}\right) \cdot p^{w k}
$$

with

$$
s^{* j}\left(\boldsymbol{r}^{* 1}, p^{* 1}, \boldsymbol{r}^{* 2}, p^{* 2}, p^{w 1}, p^{w 2}\right) \equiv \frac{E^{* j}\left(\boldsymbol{r}^{* j}, p^{* j}, p^{w j}\right)}{\sum_{k=1,2} E^{* k}\left(\boldsymbol{r}^{* k}{ }_{,} p^{* k}, p^{w k}\right)} \text { for } j=1,2
$$

The home and foreign budget constraints may then be written as

$$
\begin{aligned}
& T \cdot M(\boldsymbol{r}, p, T)=E(\boldsymbol{r}, p, T), \text { and } \\
& M^{* j}\left(\boldsymbol{r}^{* j}{ }_{,} p^{* j}{ }_{,} p^{w j}\right)=p^{w j} E^{* j}\left(\boldsymbol{r}^{* j}, p^{* j}{ }_{,} p^{w j}\right) \text { for } j=1,2 \text {. }
\end{aligned}
$$

The pair of equilibrium world prices, $\tilde{p}^{w j}\left(\boldsymbol{r}, \tau^{\mathbf{1}}, \tau^{\mathbf{2}}, \boldsymbol{r}^{* \mathbf{1}}, \tau^{* 1}, \boldsymbol{r}^{* \mathbf{2}}, \tau^{* \mathbf{2}}\right)$ for $j=1,2$, are then determined by the linkage condition (18) together with the requirement of market clearing for good $x$, 


$$
M(r, p, T)=\underset{k=1,2}{\Sigma} E^{* k}\left(r^{* k}, p^{* k}, p^{w \hbar}\right),
$$

with market clearing for good $y$ then implied by (19) and (20). As before, we assume that the Metzler- and Lerner- Paradox type outcomes are ruled out, so that $d p / d \tau^{j}>0>d p^{* j} / d \tau^{* j}$ and $d T / d \tau^{j}<0<\partial \tilde{p}^{w j} / \partial \tau^{* j}$ for $j=1,2$.

Finally, in analogy with our two-country model, we represent the objectives of the home and foreign government $j=1,2$ with the general functions $W(\boldsymbol{r}, p, T)$ and $W^{* j}\left(\boldsymbol{r}^{* j}{ }_{s} p^{* j}, \tilde{p}^{w j}\right)$, respectively. As before, we assume that, holding its regulations and its local price fixed, and provided that its regulations and local price do not imply autarky, each government would prefer an improvement in its terms of trade,

$$
W_{T}(\boldsymbol{r}, p, T)<0 \text { for } M(\boldsymbol{r}, p, T)>0 \text {, and } W_{\tilde{p}^{w j}}^{* j}\left(\boldsymbol{r}^{* j}, p^{* j}, \tilde{p}^{w j}\right)>0 \text { for } M^{* j}\left(\boldsymbol{r}^{* j}, p^{* j}, \tilde{p}^{w j}\right)>0 .
$$

We leave government objectives otherwise unrestricted.

\section{V.2: Nash Policies}

In a three-country world without international agreements, we assume that the Multilateral Nash Policy Game characterizes the equilibrium policy choices of each government. In the Multilateral Nash Policy Game, each government sets its trade and domestic regulatory policies simultaneously to maximize its objective function taking as given the policy choices of all other governments. More specifically, the home government chooses its best-response policies by solving

Program 3: $\quad \operatorname{Max}_{r, \tau^{1}, \tau^{2}} W\left(r, p\left(\tau^{j}, \tilde{p}^{w j}\right), T\right)$

taking $\boldsymbol{r}^{* \boldsymbol{j}}$ and $\tau^{* j}$ for $j=1,2$ as given, at the same time that foreign government $j$, for $j=1,2$, chooses its best-response policies by solving

Program $3^{* j}: \quad \quad \operatorname{Max}_{\boldsymbol{r}^{* j}, \tau^{* j}} W^{* j}\left(\boldsymbol{r}^{* j}, p^{* j}\left(\tau^{* j}, \tilde{p}^{w j}\right), \tilde{p}^{w j}\right)$

taking as given $\boldsymbol{r}, \tau$ and $\boldsymbol{r}^{* \boldsymbol{k}}$ and $\tau^{* k}$ for $k=1,2$ and $k \neq j$. 
At an interior solution, the resulting Nash equilibrium choices are defined by the first-order conditions:

$$
\begin{aligned}
& W_{r_{i}}+\tau^{j} W_{p} \times \frac{\partial \tilde{p}^{w j}}{\partial r_{i}}+W_{T} \times \frac{d T}{d r_{i}}=0 \text { for } i=1,2, \ldots, R, \\
& W_{p}+\theta j W_{T}=0, \text { for } j=1,2, \\
& W_{r_{i}^{* j}}^{* j} \times\left(\frac{1}{\partial \tilde{p}^{w j} / \partial r_{i}^{* j}}\right)=-\left[\frac{1}{\tau^{* j}} W_{p^{* j}}^{* j}+W_{\tilde{p}^{w j}}^{* j}\right] \text { for } i=1,2, \ldots, R^{*}, j=1,2 \text { and } \\
& W_{p^{* j}}^{* j}+\theta^{* j} W_{\tilde{p}^{w j}}^{* j}=0 \text { for } j=1,2,
\end{aligned}
$$

where, with the Metzler and Lerner paradoxes ruled out,

$$
\theta^{j} \equiv \frac{\left[d T / d \tau^{j}\right]}{\left[d p / d \tau^{j}\right]}<0 ; \quad \theta^{* j} \equiv \frac{\left[\partial \tilde{p}^{w j} / \partial \tau^{* j}\right]}{\left[d p^{* j} / d \tau^{* j}\right]}<0
$$

We observe that, by the linkage condition (18), $\tau^{1}\left[\partial \tilde{p}^{w 1} / \partial r_{i}\right]=\tau^{2}\left[\partial \tilde{p}^{w 2} / \partial r_{i}\right]$, and so (23) may be equivalently evaluated for either $j=1,2$. The home government reaction curves are defined by (23) and (24), while foreign government $j$ 's reaction curves are defined by (25) and (26), with the Nash equilibrium policy choices defined by the joint solutions to these equations.

\section{$\underline{\text { V.3: Efficient Policies }}$}

We characterize efficient policy choices in the Appendix (see the proof of Proposition 6). Here we simply define the politically optimal tariffs and regulations:

$$
W_{p}=0=W_{p^{* j}}^{* j} \text { for } j=1,2 ; W_{r_{i}}=0 \text { for } i=1,2, \ldots, R ; \text { and } W_{r_{i}^{*}}^{*}=0 \text { for } i=1,2, \ldots, R^{*}
$$

In the Appendix we prove:

Proposition 6: Politically optimal tariffs and regulations are efficient if and only if the tariffs conform to MFN. Moreover, if any country sets its politically optimal policies, then efficiency requires that all countries set their politically optimal policies and abide by MFN.

Proof: See Appendix. 


\section{V.4: Sovereignty in the Absence of International Agreements}

As with our two-country model, we next observe that the Nash policy choices defined by the simultaneous solutions to Program 3 and Program $3^{* j}$ may be written in an equivalent form in which each government's program is partitioned into a two-step choice problem. Following our twocountry presentation, we develop this partition from the perspective of the domestic government.

To this end, recall the best-response policy choice problem of the domestic government defined by Program 3. In analogy with the two-country model, in which the best-response policy choice problem contained in Program 1 was transformed into Program 1' by first introducing $\tilde{p}^{w}$ as a choice variable and adding the market-clearing condition (3) as a constraint, we now transform Program 3 by first introducing $\tilde{p}^{w 1}, \tilde{p}^{w 2}$ and $T$ as choice variables and adding the appropriate constraints. The three new constraints are the linkage condition (18), the market-clearing condition (21), and the definition of $T$ in terms of the foreign regulatory choices and the foreign local and world prices. However, rather than introduce the linkage condition explicitly, it is convenient to instead use this condition to eliminate $\tau^{2}$ as an independent choice variable in the domestic government's best-response problem. And rather than introduce explicitly the definition of $T$, it is convenient instead to use this definition to eliminate $T$ as an independent choice variable in the domestic government's best-response problem. Utilizing (18) and the definition of $T$ in this way, and using $T(\cdot)$ to denote $T\left(\boldsymbol{r}^{* 1}, p^{* 1}\left(\tau^{* 1}, \tilde{p}^{w 1}\right), \boldsymbol{r}^{* 2}, p^{* 2}\left(\tau^{* 2}, \tilde{p}^{w 2}\right), \tilde{p}^{w 1}, \tilde{p}^{w 2}\right)$, Program 3 (which takes $\boldsymbol{r}^{* j}$ and $\tau^{* j}$ for $j=1,2$ as given) can be equivalently written as

$$
\begin{aligned}
& \operatorname{Max}_{\boldsymbol{r}, \tau^{1}, \tilde{p}^{w l}, \tilde{p}^{w 2}} W\left(\boldsymbol{r}, p\left(\tau^{1}, \tilde{p}^{w 1}\right), T(\cdot)\right) \\
& \text { s.t. } \quad M\left(\boldsymbol{r}, p\left(\tau^{1}, \tilde{p}^{w I}\right), T(\cdot)\right)-\sum_{k=1,2} E^{* k}\left(\boldsymbol{r}^{* k}, p^{* k}, p^{w h}\right)=0,
\end{aligned}
$$

which is in turn equivalent to

$$
\begin{aligned}
& \operatorname{Max}_{\boldsymbol{r}, \tau^{1}, \tilde{p}^{w l}, \tilde{p}^{w 2}} W\left(\boldsymbol{r}, p\left(\tau^{1}, \tilde{p}^{w l}\right), T(\cdot)\right) \\
& \text { s.t. } \quad\left[M\left(\boldsymbol{r}, p\left(\tau^{1}, \tilde{p}^{w 1}\right), T(\cdot)\right)-M\right]+\left[M-\sum_{k=1,2} E^{* k}\left(\boldsymbol{r}^{* k}, p^{* k}, p^{w \hbar}\right)\right]=0
\end{aligned}
$$


for any $M$. Observe that, taking $\boldsymbol{r}^{* j}$ and $\tau^{* j}$ for $j=1,2$ as given, $T(\cdot)$ is determined once $\tilde{p}^{w 1}$ and $\tilde{p}^{w 2}$ are chosen.

Consider now the partition of this program into the alternative two-step program:

Program 3': Step 1. Fix $\left(M, \tilde{p}^{w 1}, \tilde{p}^{w 2}\right)$, and Max ${ }_{r, \tau^{1}} \quad W\left(r, p\left(\tau^{1}, \tilde{p}^{w 1}\right), T\right)$

$$
\text { s.t. } \quad\left[M\left(r, p\left(\tau^{1}, \tilde{p}^{w l}\right), T\right)-M\right]=0 \text {. }
$$

$$
\begin{gathered}
\text { Step 2. } \operatorname{Max}_{M, \tilde{p}^{w 1}, \tilde{p}^{w 2}} \quad Y\left(\boldsymbol{r}\left(M, \tilde{p}^{w 1}{ }_{s} \tilde{p}^{w 2}\right), p\left(\tau^{1}\left(M, \tilde{p}^{w 1}, \tilde{p}^{w 2}\right), \tilde{p}^{w 1}\right), T(\cdot), M, \tilde{p}^{w 1}, \tilde{p}^{w 2}\right) \\
\text { s.t. } \quad\left[M-\sum_{k=1,2} E^{* k}\left(\boldsymbol{r}^{* k}{ }_{,} p^{* k}{ }_{,} p^{w k}\right)\right]=0
\end{gathered}
$$

where $\boldsymbol{r}\left(M, \tilde{p}^{w 1}, \tilde{p}^{w 2}\right)$ and $\tau^{1}\left(M, \tilde{p}^{w 1}, \tilde{p}^{w 2}\right)$ are the solutions from Step 1 and $Y$ is the Step-1 Lagrangean. For future reference, we denote by $Z$ the Lagrangean associated with the Step- 2 sub-problem.

Using the Envelope theorem, and with $\delta$ denoting the Lagrange multiplier associated with $Y$ and $\rho$ denoting the Lagrange multiplier associated with $Z$, the first-order conditions associated with the domestic government's Step-1 program are then

$$
\begin{aligned}
& W_{r_{i}}+\delta M_{r_{i}}=0 \text { for } i=1,2, \ldots, R, \text { and } \\
& W_{p}+\delta M_{p}=0
\end{aligned}
$$

while the first-order conditions associated with the domestic government's Step-2 program are

$$
\begin{aligned}
& \frac{\partial Z}{\partial M}=-\delta+\rho=0 \\
& \frac{\partial Z}{\partial \tilde{p}^{w l}}=\tau^{1} W_{p}+\delta \tau^{1} M_{p}+\left[W_{T}+\delta M_{T}\right] \times\left[\frac{1}{\tau^{* 1}} \frac{\partial T}{\partial p^{* 1}}+\frac{\partial T}{\partial \tilde{p}^{w l}}\right]-\rho\left[\frac{1}{\tau^{* 1}} E_{p^{* 1}}^{* 1}+E_{p^{w 1}}^{* 1}\right]=0
\end{aligned}
$$




$$
\frac{\partial Z}{\partial \tilde{p}^{w 2}}=\left[W_{T}+\delta M_{T}\right] \times\left[\frac{1}{\tau^{* 2}} \frac{\partial T}{\partial p^{* 2}}+\frac{\partial T}{\partial \tilde{p}^{w 2}}\right]-\rho\left[\frac{1}{\tau^{* 2}} E_{p^{* 2}}^{* 2}+E_{p^{w 2}}^{* 2}\right]=0
$$

We may now state:

Lemma 3: Program 3 and Program 3' are equivalent ways of characterizing the domestic government's best-response policies for any $\boldsymbol{r}^{* 1}, \tau^{* 1}, \boldsymbol{r}^{* 2}$ and $\tau^{* 2}$.

Proof: See Appendix.

In exact analogy with our two-country model, we may by Lemma 3 utilize the two-step representation of the domestic government's best-response policies developed just above to characterize the nature and degree of national sovereignty enjoyed by the domestic government in the Multilateral Nash Policy Game. As in the two-country setting, an examination of the domestic government's Step-1 choice problem indicates that it enjoys (both interdependence and Westphalian) sovereignty over these choices. Similarly, an examination of the domestic government's Step-2 choice problem indicates that, except for the case of absolute isolation, the domestic government enjoys neither interdependence sovereignty nor Westphalian sovereignty over these choices.

Finally, it may be established as in the two-country setting that the partition embodied in Program 3' identifies the maximal sovereign choice set over all partitions of the domestic government's best-response policy choices. Denoting by $I\left(M_{s} \tilde{p}^{w 1}, \tilde{p}^{w 2}\right)$ the (length $\left.R+1\right)$ vector of policy instruments chosen by the domestic government in its Step-1 problem (namely, $\boldsymbol{r}\left(M, \tilde{p}^{w 1}, \tilde{p}^{w 2}\right.$ ) and $\tau^{1}\left(M, \tilde{p}^{w 1}, \tilde{p}^{w 2}\right)$ ), we may thus conclude that, as described by the unilateral choice function $\boldsymbol{I}\left(M, \tilde{p}^{w 1}, \tilde{p}^{w 2}\right)$, the choices that the domestic government makes over its maximal sovereign choice set concern everything that it cares about except the level of market access it affords to each of the two foreign countries (as defined by the volume of imports it would accept at a particular pair of bilateral world prices). Hence, as in the two-country setting, we associate in our three-country model the domestic government's sovereign choices with the domestic government's unilateral choice function $\boldsymbol{I}\left(M, \tilde{p}^{w 1}, \tilde{p}^{w 2}\right)$. Observing that foreign countries 1 and 2 are exactly analogous to the foreign 
country in the two-country model, we may also denote the sovereign choice function of foreign government $j$ for $j=1,2$, by $\boldsymbol{I}^{* \boldsymbol{j}}\left(M^{* j}, \tilde{p}^{w j}\right)$.

\section{V.5: Sovereignty and Non-discrimination}

We may now ask the central question of this section: Is the domestic government's sovereignty compromised if it agrees to abide by a non-discrimination rule? Broadly speaking, we may think of the answer to this question as indicating whether a government's national sovereignty would be compromised if it joined the GATT/WTO but made no market access commitments, and therefore simply agreed to abide by the MFN principle of the GATT/WTO. We answer this question in two parts.

First, above we have defined the domestic government's sovereignty over a policy instrument in $I$ to be directly compromised by an international agreement whenever limits on that policy instrument are directly negotiated between it and a foreign government. Clearly the nondiscrimination rule is a negotiated limit on the domestic government's tariff instruments, of the form $\tau^{1}=\tau^{2}$. However, $\boldsymbol{I}\left(M, \tilde{p}^{w 1}, \tilde{p}^{w 2}\right)$ includes only the tariff $\tau^{1}$, not both $\tau^{1}$ and $\tau^{2}$ : given domestic market access levels determined by $M, \tilde{p}^{w 1}$ and $\tilde{p}^{w 2}$, the tariff $\tau^{2}$ is determined by the linkage condition (18) once $\tau^{1}$ is chosen, and so as we observed in the previous subsection $\tau^{2}$ is not an independent choice variable once domestic market access levels are given. The non-discrimination rule, then, does not restrict $\tau^{1}$, and so it does not place limits on any policy instrument in $I$. Hence, we may conclude that the domestic government's sovereignty over its tariff instruments is not directly compromised when it accepts a non-discrimination rule.

The remaining question is whether the domestic government's sovereignty is indirectly compromised, and this is the focus of the second part of our answer. To provide an answer, we now observe using the linkage condition (18) that the MFN rule restricts the feasible Step- 2 choices of $\tilde{p}^{w 1}$ and $\tilde{p}^{w 2}$ to those that satisfy $\tilde{p}^{w 1}=\tilde{p}^{w 2}$, but as we noted just above leaves the Step-1 choices of the 
domestic government $\boldsymbol{I}\left(M, \tilde{p}^{w 1}, \tilde{p}^{w 2}\right)$ unrestricted given its Step-2 choices. Accordingly, we may conclude that the domestic government's sovereignty is not compromised indirectly when it agrees to abide by the non-discrimination rule. We may therefore state:

Proposition 7: Abiding by the non-discrimination rule does not compromise national sovereignty.

Proposition 7 reflects the following intuition. Discriminatory tariffs make possible certain market access choices that would be impossible under MFN. But market access (Step-2) choices lack interdependence sovereignty and Westphalian sovereignty in the Multilateral Nash Policy Game. Therefore, for these choices, the MFN restriction can not take away sovereignty that governments did not possess in the first place. And given any market access choices that would be feasible under MFN, discriminatory tariffs do not create any additional possibilities relative to MFN tariffs for delivering these market access levels. This feature is reflected in the fact that the Step-1 choices of Program 3' may be expressed as choices over domestic regulations $\boldsymbol{r}$ and a single tariff $\tau^{1}$. Hence, for these decisions, which are the (Step-1) decisions over which governments enjoy sovereignty in the Multilateral Nash Policy Game, the MFN restriction has no bearing. ${ }^{11}$

Thus far we have maintained an assumption in the three-country model (consistent with our two-country model) that all countries are "large," in the sense that each has an impact on world prices when it alters its policies. In the next subsection, we consider the possibility that some countries might be "small," and so do not alter world prices when they alter their policies. ${ }^{12}$ However, before turning to a setting in which some countries are large and some are small, we record a final result for the world in which all countries are large.

\footnotetext{
${ }^{11}$ It is worth emphasizing that this feature extends naturally to a setting with more than two foreign countries. With $N>2$ foreign countries, there are then $N-1$ linkage conditions analogous to (18), implying that given $M$ and the set of $\left\{\tilde{p}^{w j}\right\}$ ' s only one $\tau^{i}$ remains to be determined.

${ }^{12}$ If all countries are small, then it can be shown that the Multilateral Nash Policy Game yields policy choices that are efficient from an international perspective, and so there would be no reason for an international agreement to exist in this case (see Bagwell and Staiger, 1999, 2001).
} 
In light of Propositions 5 and 7, we may state:

Proposition 8: If all countries are "large," market access agreements that require governments to abide by the non-discrimination rule preserve the national sovereignty of each government.

\section{V.6: The Sovereignty of Small Countries}

We now treat foreign country 2 as a foreign region which is composed of a continuum of identical "small" countries, no one of which individually has any impact on world markets. We observe that, in light of the assumed symmetry of countries within region 2, the domestic government will not discriminate across foreign countries within region 2 in a symmetric Nash equilibrium (i.e., the domestic government's best-response tariffs will continue to consist of a tariff $\tau^{1}$ against imports from foreign country 1 and a tariff $\tau^{2}$ against imports from all foreign countries residing in region 2).

It can immediately be seen that Program 3' continues to provide a valid two-step representation of the domestic government's best-response choices of $\boldsymbol{r}, \tau^{1}$ and $\tau^{2}$ given any $\boldsymbol{r}^{* 1}$ and $\tau^{* 1}$ imposed by foreign country 1 and any $\boldsymbol{r}^{* 2}$ and $\tau^{* 2}$ imposed symmetrically by each foreign country in region 2. This means in turn that, in the (symmetric) equilibrium of the Multilateral Nash Policy Game, the domestic government continues to enjoy sovereignty over its Step- 1 choices, and it continues to lack both interdependence sovereignty and Westphalian sovereignty in its Step-2 choices, when foreign region 2 is interpreted as being composed of many small countries. An analogous statement applies to foreign country 1: the government of foreign country 1 continues to enjoy sovereignty over its Step-1 choices $\boldsymbol{I}^{* 1}\left(M^{* 1}{ }_{\vec{p}}^{w I}\right)$ in the Multilateral Nash Policy Game, and it continues to lack both interdependence sovereignty and Westphalian sovereignty in its Step-2 choices $\left(M^{* 1}, \tilde{p}^{w 1}\right)$, when foreign region 2 is interpreted as being composed of many small countries.

However, an important difference arises in the Multilateral Nash Policy Game with respect to the sovereignty enjoyed by the small foreign countries of region 2. A representative foreign 
government $c$ in region 2, being small, takes the market clearing world price for trade between the domestic country and region $2, \hat{p}^{w 2}$, as given and fixed at $\hat{p}^{w 2}=\hat{p}^{w 2}\left(\boldsymbol{r}, \tau^{1}, \tau^{2}, \boldsymbol{r}^{* 1}, \tau^{* 1}, \boldsymbol{r}^{* 2}, \tau^{* 2}\right)$, where $\boldsymbol{r}^{* 2}$ and $\tau^{* 2}$ represent the (symmetric) policy levels of all other small countries in foreign region 2 . As a general matter, world prices are taken as fixed (at the levels implied by Step- 2 choices) in the Step1 choice problem, and so the Step-1 choice problem for this representative region-2 government is not altered from before. Specifically, letting " c" denote variables associated with a representative region-2 government, its Step-1 program is:

$$
\begin{aligned}
& \text { Step 1. Fix }\left(M^{* c}, \tilde{p}^{w 2}\right) \text {, and } \operatorname{Max}_{\boldsymbol{r}^{* c}, \tau^{* c}} W^{* c}\left(\boldsymbol{r}^{* c}, p^{* c}\left(\tau^{* c}, \tilde{p}^{w 2}\right), \tilde{p}^{w 2}\right) \\
& \text { s.t. }\left[M^{* c}\left(\boldsymbol{r}^{* c}, p^{* c}\left(\tau^{* c}, \tilde{p}^{w 2}\right), \tilde{p}^{w 2}\right)-M^{* c}\right]=0 .
\end{aligned}
$$

But with $L^{* c}$ denoting the Lagrangean associated with $c$ 's Step-1 program, and with $\left(\boldsymbol{r}^{* c}\left(M^{* c}, \tilde{p}^{w 2}\right), \tau^{* c}\left(M^{* c}, \tilde{p}^{w 2}\right)\right)$ denoting the choices that solve $c$ 's Step-1 program, the Step-2 choice problem for this representative region-2 government is now:

$$
\begin{aligned}
\text { Step 2. } \operatorname{Max}_{M^{* c}, \tilde{p}^{w 2}} L^{* c}\left(\boldsymbol{r}^{* c}\left(M^{* c}, \tilde{p}^{w 2}\right), p^{* c}\left(\tau^{* c}\left(M^{* c}, \tilde{p}^{w 2}\right), \tilde{p}^{w 2}\right), M^{* c}, \tilde{p}^{w 2}\right) \\
\text { s.t. } \quad \tilde{p}^{w 2}-\tilde{p}^{w 2}\left(\boldsymbol{r}, \tau^{1}, \tau^{2}, \boldsymbol{r}^{* 1}, \tau^{* 1}, \boldsymbol{r}^{* 2}, \tau^{* 2}\right)=0 .
\end{aligned}
$$

Evidently, while the Step-2 choices of the government of a representative small country in region 2 lack interdependence sovereignty in the extreme - the constraint imposed by the policies of all other countries now completely dictates the relevant world price $\tilde{p}^{w 2}$ for the government of country $c$ - these Step- 2 choices now do reflect Westphalian sovereignty: with the government of country $c$ unable to alter $\tilde{p}^{w 2}\left(\boldsymbol{r}, \tau^{1}, \tau^{2}, \boldsymbol{r}^{* 1}, \tau^{* 1}, \boldsymbol{r}^{* \mathbf{2}}, \tau^{* 2}\right)$ with its Step-2 choices, all other governments are indifferent to the outcome of its Step- 2 choice problem. As small countries thus enjoy a degree of sovereignty in their market access (Step-2) choices in the Multilateral Nash Policy Game, we now broaden our notion of sovereignty preservation accordingly and observe that the (Westphalian) sovereignty of a small country is directly compromised when it accepts a market access commitment as a result of an international negotiation. We may therefore state:

Proposition 9: The sovereignty of the government of a small country cannot be preserved in an international agreement in which it is asked to make market access commitments. 
To see whether there are circumstances under which the attainment of international efficiency is nevertheless consistent with the preservation of national sovereignty when small countries are present, observe now that the best-response policy choices of the representative government $c$ solve

$$
W_{p^{* c}}^{* c}=0=W_{r_{i}^{* c}}^{* c} \text { for } 1=1,2, \ldots, R^{* c}
$$

which by (27) corresponds to the politically optimal policy choices for this government. Hence, if a small country is not asked to make market access commitments in a trade agreement, it will implement its politically optimal policies. Accordingly, by Propositions 6 and 9, international efficiency can be consistent with preservation of the sovereignty of small countries only if MFN is imposed. But by Proposition 7, the MFN rule itself entails no sacrifice of national sovereignty. ${ }^{13}$ Referring to politically optimal market access agreements as market access agreements which achieve the market access levels implied by politically optimal policies, we may now state:

Proposition 10: If some (but not all) countries are "small," then achieving international efficiency and preserving national sovereignty are mutually consistent goals of an international agreement if and only if the agreement satisfies the MFN requirement. In particular, politically optimal market access agreements that require governments to abide by the non-discrimination rule provide the unique path to achieving international efficiency while preserving national sovereignty in this setting.

In effect, if small countries are asked to make market access commitments, their Westphalian sovereignty will be compromised, as Proposition 9 reflects. If this is to be avoided, then small countries must be left unconstrained to choose their best-response policies in any international agreement. This requirement, though, is consistent with international efficiency only when tariffs also conform to the MFN requirement, as indicated by Proposition 6. As a consequence, Proposition 10 suggests that a non-discrimination rule is "complementary" to preserving the national sovereignty

\footnotetext{
${ }^{13}$ While Proposition 7 is derived in a setting where all countries are large, in the current setting each small foreign country trades only with the domestic country, and so an MFN requirement does not apply to small countries, guaranteeing that the result of Proposition 7 extends to the current setting as well. Moreover, even if a small country had multiple trading partners, its inability to affect world prices implies that any attempt by it to set discriminatory tariffs would simply prohibit trade between it and all but its most-favored (lowest-tariff) trading partner, thereby ensuring that it has no incentive to deviate from non-discriminatory tariffs in a Nash equilibrium (and that an MFN requirement would therefore not compromise its sovereignty).
} 
of small countries in the following sense: the (Westphalian) sovereignty of small countries can be preserved under an internationally efficient agreement only if that agreement abides by the MFN requirement. More broadly, and in light of our finding in Proposition 7 that the MFN requirement itself involves no compromise of national sovereignty, our three-country results therefore suggest that a non-discrimination rule coupled with a market access agreement can facilitate the attainment of internationally efficient outcomes which do not compromise national efficiency.

When viewed together, the results from this and the previous section have potentially important implications for the design of the World Trade Organization (WTO) and its predecessor, the General Agreement on Tariffs and Trade (GATT). The GATT/WTO has from its inception been concerned most fundamentally with non-discriminatory market access commitments, and it has traditionally sought to anchor these commitments with negotiations over border measures (e.g., tariffs) that are "multilateralized" through the MFN requirement. But this tradition is being eroded

on two fronts. First, the extent and importance of discriminatory trade agreements (permitted by GATT/WTO exceptions to its MFN requirement) has increased dramatically in recent decades. And second, increasingly the WTO is thought of as a potential forum for the negotiation of international commitments on a host of non-border policies that are deemed to have important market access consequences, ranging from labor standards to environmental regulations to competition policy. Our results highlight the fundamental implications of these developments for the potential conflicts between international efficiency and national sovereignty within the WTO. Specifically, as our results indicate, the further the WTO departs from facilitating agreements that take the form of nondiscriminatory market access commitments, the more it is likely to pose a (direct and indirect - and in principle, unnecessary) threat to the sovereignty of its member governments.

\section{National Sovereignty and International Institutions}

The essential logic from our analysis thus far boils down to a simple message: identify the transmission mechanism of the international externality, write international agreements directly over this transmission mechanism, and you can achieve international efficiency at the cost of a modest (and possibly zero) sacrifice of national sovereignty. When the international externalities that create 
international inefficiency are of a pecuniary nature, the transmission mechanism takes a specific form: market access. What happens, though, when international externalities of a non-pecuniary nature arise? Externalities of this nature are the primary focus of the large literature on fiscal federalism that began with Oates (1972) and is extended to an explicitly international context in the work of Alesina and Spolaore (1997), Alesina, Angeloni and Etro (2003) and others. In this section, we briefly explore one facet of the relationship between national sovereignty and international efficiency when international externalities take a non-pecuniary form. ${ }^{14}$

Specifically, we focus on an important distinction that arises between pecuniary and nonpecuniary externalities. Pecuniary externalities give rise to inefficiency only if agents (in this case governments) wield market power and can therefore affect prices (in this case world prices) with their actions. In the case of non-pecuniary externalities, by contrast, inefficiency typically arises even when all agents are small and there is no market power affecting decisions.

The importance of this distinction for issues of national sovereignty can be appreciated by noting that "small" countries by definition enjoy Westphalian sovereignty in all their decisions. In the case of international pecuniary externalities, we have seen that small countries enjoy Westphalian sovereignty in their market access choices of the Multilateral Nash Policy Game, while large countries do not. But in a sense, where international pecuniary externalities are involved, it is also the large countries - not the small - that are creating the international inefficiency. This suggests that, in the case of international pecuniary externalities, there is no inherent conflict between preserving Westphalian sovereignty and achieving international efficiency through an international agreement, because only the large countries need expand their market access beyond unilaterally chosen levels to achieve international efficiency, and this requires of them no compromise of (Westphalian) sovereignty. This suggestion is formalized in Propositions 10.

\footnotetext{
${ }^{14} \mathrm{~A}$ more systematic exploration of national sovereignty in the case where important international externalities of a non-pecuniary nature exist must consider how the presence of such externalities would affect the partitions of the government choice problems that we have exploited in this paper. We leave this to future work.
} 
In the case of international non-pecuniary externalities, however, a group of countries will typically contribute to the international inefficiency even when each country within that group is "small" with regard to this externality, and therefore even if each country within that group enjoys Westphalian sovereignty with respect to decisions that impact the externality. This suggests that, in contrast to the case of international pecuniary externalities, when important international nonpecuniary externalities are present, governments may face an inescapable tradeoff between international efficiency and (Westphalian) sovereignty. This tradeoff is illustrated most starkly in

a hypothetical case where all countries are small in the dimension of an international non-pecuniary externality. In that case, in the absence of an international agreement, all countries enjoy Westphalian sovereignty in decisions that impact this externality. Nevertheless, even though all countries are small, the existence of the international non-pecuniary externality typically creates an international inefficiency, and the attainment of international efficiency therefore requires that Westphalian sovereignty over decisions that impact this externality must be sacrificed.

This discussion suggests that, when it comes to issues of national sovereignty as they arise in the context of efforts to solve international problems, not all international problems are alike. In particular, international problems that reflect inefficiencies that are fundamentally driven by trade have a particular structure - they concern international pecuniary externalities - which implies the absence of any inherent conflict between international efficiency and national sovereignty. By contrast, confronting international problems that derive from international non-pecuniary externalities is likely to pose a more direct efficiency/sovereignty tradeoff.

\section{Conclusion}

What are the sovereign rights of nations in an interdependent world, and to what extent do these rights stand in the way of achieving important international objectives? In this paper, we have proposed answers to these two questions. Our answers, of course, depend on the definition of national sovereignty. We have formally defined two features of sovereignty - unilateral control and internal affairs - that we believe are central to the respective notions of interdependence sovereignty and Westphalian sovereignty emphasized in the political science literature. And using these 
definitions, we have shown how Nash choice problems can be partitioned in a way that allows a characterization of the degree and nature of sovereignty that governments possess in the Nash equilibrium. This characterization, in turn, provides a benchmark from which to formally assess the implications for national sovereignty of international agreements of various designs. In regard to this assessment, we report two broad findings.

First, in the context of international commercial relations, we find that in principle there is no inherent conflict between the twin objectives of attaining international efficiency through international agreements and preserving national sovereignty. And we find that a number of the foundational aspects of the GATT/WTO, such as its emphasis on market access commitments and the MFN rule, are in harmony with these twin objectives. In this regard, we give formal support to the observation of Rabkin (1998):

"Probably the single most effective and consequential international program of the postwar era has been the mutual reduction of trade barriers under the General Agreement on Tariffs and Trade, initiated in 1947. Reasonable questions may be raised about certain aspects of the World Trade Organization, established in 1995 to help administer GATT norms. But, fundamentally, the trading system is quite compatible with traditional notions of sovereignty. It was developed on the foundations of much older sorts of international agreement, which would have been quite recognizable to the Framers of the Constitution.” Rabkin, pp. 85-86.

However, our results also suggest that the maintenance of this compatibility depends crucially on being true to these fundamental principles: the further away the WTO moves from a market-access focus and adherence to MFN, the more likely will conflicts arise within the WTO between international efficiency and national sovereignty.

Our second broad finding is that, in the universe of international relations among national governments, commercial relations are special, because trade problems that warrant international attention reflect international externalities of a pecuniary nature. Pecuniary externalities give rise to a distinctive structure that, as we have demonstrated, suggests a natural harmony between national sovereignty and international efficiency. In contrast, to the extent that governments are interdependent as a result of non-pecuniary externalities, we suggest that the conflicts between international efficiency and national sovereignty may be inescapable. 


\section{References}

Alesina, Alberto and Enrico Spolaore, "On the Number and Size of Nations," Quarterly Journal of Economics, November 1997, pp. 1027-56.

Alesina, Alberto, Ignazio Angeloni and Federico Etro, "International Unions," mimeo, Harvard University, March 2003.

Bagwell, Kyle, and Robert W. Staiger, "An Economic Theory of GATT," American Economic Review, March 1999, pp. 215-248.

Bagwell, Kyle, and Robert W. Staiger, "Domestic Policies, National Sovereignty and International Economic Institutions," Quarterly Journal of Economics, May 2001, pp. 519-562.

Bagwell, Kyle, and Robert W. Staiger, "The WTO as a Mechanism for Securing Market Access Property Rights: Implications for Global Labor and Environmental Issues," Journal of Economic Perspectives, Summer 2001, pp. 69-88.

de Vattel, Emmerich, The Law of Nations, Translated by Joseph Chitty, T.\& J. W. Johnson \& Co., Law Booksellers, Philadelphia. 1872.

Krasner, Stephen D. Sovereignty: Organized Hypocrisy, Princeton University Press. 2001.

Oates, Wallace, Fiscal Federalism, New York, Harcourt Brace Jovanovich, 1972.

Rabkin, Jeremy, Why Sovereignty Matters, The AEI Press, Washington D.C.. 1998. 


\section{Appendix}

In this Appendix, we provide proofs of all lemmas and propositions that are not proved in the body of the paper.

Lemma 1: Program 1 and Program 1' are equivalent ways of characterizing the domestic government's best-response policies for any $\boldsymbol{r}^{*}$ and $\tau^{*}$.

Proof: We prove this by establishing that the first-order conditions associated with Program 1', (13)(16), are equivalent to the first-order conditions associated with Program 1,(5)-(6). To establish this, we first use (3) to derive

$$
\frac{\partial \tilde{p}^{w}}{\partial \tau}=\frac{\tilde{p}^{w} M_{p}}{\left[\left(\frac{1}{\tau^{*}} E_{p^{*}}^{*}+E_{p^{w}}^{*}\right)-\left(\tau M_{p}+M_{p^{w}}\right)\right]}
$$

With this expression, and using (15) and (16) to eliminate $\lambda$ from (14), it is then direct to verify that (6) and (14) are equivalent. Similarly, we use (3) to derive

$$
\frac{\partial \tilde{p}^{w}}{\partial r_{i}}=\frac{M_{r_{i}}}{\left[\left(\frac{1}{\tau^{*}} E_{p^{*}}^{*}+E_{p^{w}}^{*}\right)-\left(\tau M_{p}+M_{p^{w}}\right)\right]} \text { for } i=1,2, \ldots, R
$$

With this expression, and using (15) and (16) to eliminate $\lambda$ from (13), it is then direct to verify that (5) and (13) are equivalent.

Proposition 6: Politically optimal tariffs and regulations are efficient if and only if the tariffs conform to MFN. Moreover, if any country sets its politically optimal policies, then efficiency requires that all countries set their politically optimal policies and abide by MFN.

Proof: To prove this proposition, we first characterize the efficiency frontier of the 3-country model.

To this end, fix foreign welfare levels $\bar{W}^{* j}$ for $j=\{1,2\}$ and define $\tilde{p}^{w j}\left(\boldsymbol{r}^{* j}, \tau^{* j}, \bar{W}^{* j}\right)$ implicitly by

$$
W^{* j}\left(\boldsymbol{r}^{* j}{ }_{,} p^{* j}\left(\tau^{* j}{ }_{,} \tilde{p}^{w j}\right), \tilde{p}^{w j}\right)=\bar{W}^{* j} \text { for } j=\{1,2\}
$$

Observe that 
(A1) $\frac{\partial \tilde{p}^{w j}}{\partial \tau^{* j}}=\frac{p^{* j} W_{p^{* j}}^{* j}}{\left[W_{p^{* j}}^{* j}+\tau^{* j} W_{\tilde{p}^{w j}}^{* j}\right]}$; and $\frac{\partial \tilde{p}^{w j}}{\partial r_{i}^{* j}}=-\frac{\tau^{* j} W_{r_{i}^{* j}}^{* j}}{\left[W_{p^{* j}}^{* j}+\tau^{* j} W_{\tilde{p}^{w j}}^{* j}\right.}$,

for $i=1,2, \ldots, R^{* j}$ and $j=\{1,2\}$. We may now define

$$
\bar{T}\left(\left\{\boldsymbol{r}^{* j}\right\},\left\{\tau^{* j}\right\},\left\{\bar{W}^{* j}\right\}\right) \equiv T\left(\left\{\boldsymbol{r}^{* j}\right\},\left\{\boldsymbol{p}^{* j}\left(\tau^{* j}, \tilde{p}^{w j}\left(\boldsymbol{r}^{* j}, \tau^{* j}, \bar{W}^{* j}\right)\right)\right\},\left\{\tilde{p}^{w j}\left(\boldsymbol{r}^{* j}, \tau^{* j}, \bar{W}^{* j}\right)\right\}\right),
$$

and observe that, by the market-clearing condition (21), a value of $p$ is implied, which we denote by $\bar{p}\left(\boldsymbol{r},\left\{\boldsymbol{r}^{* j}\right\},\left\{\tau^{* j}\right\},\left\{\bar{W}^{* j}\right\}\right)$. We may thus write domestic government welfare as a function of the domestic regulatory choices, the foreign regulatory choices and foreign tariffs, and the foreign welfare levels, or

$$
W\left(\boldsymbol{r}, \bar{p}\left(\boldsymbol{r},\left\{\boldsymbol{r}^{* j}\right\},\left\{\tau^{* j}\right\},\left\{\bar{W}^{* j}\right\}\right), \bar{T}\left(\left\{\boldsymbol{r}^{* j}\right\},\left\{\tau^{* j}\right\},\left\{\bar{W}^{* j}\right\}\right)\right)
$$

Fixing foreign welfare levels and choosing domestic and foreign regulations and foreign tariffs to maximize domestic welfare given by (A2) then defines a point on the efficiency frontier. The first order conditions that define the efficiency frontier are

$$
W_{r_{i}}+W_{p} \frac{\partial \bar{p}}{\partial r_{i}}=0 \text { for } i=1,2, \ldots, R
$$

$$
\begin{aligned}
& W_{p} \frac{\partial \bar{p}}{\partial r_{i}^{* j}}+W_{\bar{T}} \frac{\partial \bar{T}}{\partial r_{i}^{* j}}=0 \text { for } i=1,2, \ldots, R^{* j} \text { and } j=1,2, \text { and } \\
& W_{p} \frac{\partial \bar{p}}{\partial \tau^{* j}}+W_{\bar{T}} \frac{\partial \bar{T}}{\partial \tau^{* j}}=0 \text { for } j=1,2 .
\end{aligned}
$$

By (27) and (A3)-(A5), politically optimal tariffs and regulations are efficient if and only if

$$
\frac{\partial \bar{T}}{\partial r_{i}^{* j}}=0=\frac{\partial \bar{T}}{\partial \tau^{* j}} \text { for } i=1,2, \ldots, R^{* j} \text { and } j=1,2 \text {. }
$$

But by (A1), (A6) is satisfied at the political optimum if and only if

$$
\frac{E_{r_{i}^{* j}}^{* j}}{M}\left[\tilde{p}^{w j}-\bar{T}\right]=0=\frac{E_{p^{* j}}^{* j}}{M}\left[\tilde{p}^{w j}-\bar{T}\right] \text { for } i=1,2, \ldots, R^{* j} \text { and } j=1,2
$$

Hence, by (A7), politically optimal tariffs and regulations are efficient if and only if the tariffs 
conform to MFN (so that $\tilde{p}^{w j}=\bar{T}$ for $j=1,2$ ). Further, if any country's policies are set at their politically optimal levels, then (A1)-(A7) can be used to show that efficiency requires that all countries set their politically optimal policies and abide by MFN.

\section{QED}

Lemma 3: Program 3 and Program 3' are equivalent ways of characterizing the domestic government's best-response policies for any $\boldsymbol{r}^{* 1}, \tau^{* 1}, \boldsymbol{r}^{* 2}$ and $\tau^{* 2}$.

Proof: We prove this by establishing that the first-order conditions associated with Program 3', (30)(32), are equivalent to the first-order conditions associated with Program 3, (23)-(26). To this end, we first use (30) and (32) to derive an expression for $\delta$, which allows (29) to be written as

$$
W_{p}+\left[\frac{M_{p}\left[d T / d \tilde{p}^{w 2}\right]}{\left[d E^{* 2} / d \tilde{p}^{w 2}\right]-M_{T}\left[d T / d \tilde{p}^{w 2}\right]}\right] W_{T}=0
$$

Next, we observe that (24) implies $\theta^{1}=\theta^{2}$, which can be manipulated to yield

$$
\frac{\partial \tilde{p}^{w 1}}{\partial \tau^{2}}=\left[\frac{\tilde{p}^{w 2}}{\tilde{p}^{w 1}}\right]\left[\frac{d T / d \tilde{p}^{w 2}}{d T / d \tilde{p}^{w 1}}\right]\left[\frac{\partial \tilde{p}^{w 2}}{\partial \tau^{1}}\right]
$$

which in turn allows $\theta^{2}$ to be written as

$$
\theta^{2}=\frac{\left[d T / d \tilde{p}^{w 2}\right]\left\{\left[\partial \tilde{p}^{w 2} / \partial \tau^{2}\right]+\left(\tilde{p}^{w 2} / \tilde{p}^{w 1}\right)\left[\partial \tilde{p}^{w 2} / \partial \tau^{1}\right]\right\}}{\tilde{p}^{w 2}+\tau^{2}\left[\partial \tilde{p}^{w 2} / \partial \tau^{2}\right]}
$$

Using the linkage condition (18) and the market-clearing condition (21), expressions for $\partial \tilde{p}^{w 2} / \partial \tau^{1}$ and $\partial \tilde{p}^{w 2} / \partial \tau^{2}$ may be derived which, when substituted into (A10), yield

$$
\theta^{2}=\left[\frac{M_{p}\left[d T / d \tilde{p}^{w 2}\right]}{\left[d E^{* 2} / d \tilde{p}^{w 2}\right]-M_{T}\left[d T / d \tilde{p}^{w 2}\right]}\right]
$$

Therefore, by substituting (A11) into (24) and observing that the resulting expression is identical to (A8), we may conclude that (30), (32) and (29) imply (24). Similarly, we use (30) and (31) to derive an alternative expression for $\delta$, which allows (28) to be written as

$$
W_{r_{i}}+\tau^{1} W_{p}\left[\frac{M_{r_{i}}}{\left[d E^{* 1} / d \tilde{p}^{w 1}\right]-\left[d M / d \tilde{p}^{w 1}\right]}\right]+W_{T}\left[\frac{d T}{d \tilde{p}^{w 1}}\right]\left[\frac{M_{r_{i}}}{\left[d E^{* 1} / d \tilde{p}^{w 1}\right]-\left[d M / d \tilde{p}^{w 1}\right]}\right]=0
$$


Now using (18) and (21), we may derive that

(A13) $\frac{\partial \tilde{p}^{w 1}}{\partial r_{i}}=\left[\frac{M_{r_{i}}}{\left[d E^{* 1} / d \tilde{p}^{w 1}\right]-\left[d M / d \tilde{p}^{w 1}\right]}\right]$.

Substituting (A13) into (A12) yields an expression identical to (23). Hence, we may conclude that (30), (31) and (28) imply (23). QED 